\title{
A PAIR-Wise APPROACH TO TESTING FOR OUTPUT AND GROWTH CONVERGENCE
}

\author{
M. HASHEM PESARAN \\ CESIFO WORKING PAPER NO. 1308 \\ CATEgORY 6: MONETARY Policy and InTERnATIONAL FinanCE \\ OCTOBER 2004
}

\footnotetext{
An electronic version of the paper may be downloaded

- from the SSRN website:

www.SSRN.com

- from the CESifo website:

www.CESifo.de
} 


\title{
A PAIR-WiSE APPROACH TO TESTING FOR OUTPUT AND GROWTH CONVERGENCE
}

\begin{abstract}
This paper proposes a pair-wise approach to testing for output convergence that considers all $\mathrm{N}(\mathrm{N}-1) / 2$ possible pairs of log per capita output gaps across $\mathrm{N}$ economies. A general probabilistic definition of output convergence is also proposed, which suggests that all such output gap pairs must be stationary with a constant mean. The approach is compatible with individual output series having unit roots, does not involve the choice of a reference country in computation of output gaps, and can be applied when $\mathrm{N}$ is large relative to $\mathrm{T}$ (the time dimension of the panel). The proposed test is applied to output series in the Penn World Tables over 1950-2000, as well as to Maddion's historical series over 1870-2000. Overall, the results do not support output convergence, and suggest that the findings of convergence clubs in the literature might be spurious. However, significant evidence of growth convergence is found, a result which is reasonably robust to the choice of the sample period and country groupings. Non-convergence of log per capita outputs combined with growth convergence suggests that while common technological progress seems to have been diffusing reasonably widely across economies, there are nevertheless important country-specific factors (for example, wars, famines, revolutions, regime and institutional changes) that render output gaps highly persistent, such that we can not be sure that the probability for the output gaps to lie within a fixed range will be non-zero.
\end{abstract}

JEL Code: C32, C33, D90, O47.

Keywords: economic growth, panel data models, common technological shocks, convergence.

\author{
M. Hashem Pesaran \\ Faculty of Economics and Politics \\ University of Cambridge \\ Austin Robinson Building \\ Sidgwick Avenue \\ Cambridge, CB3 9DD \\ United Kingdom \\ mhp1@econ.cam.ac.uk
}

I am grateful to Mutita Akusuwan for excellent research assistance and for carrying out all the results reported in this paper. I have benefited greatly from discussions with Steven Durlauf and Ron Smith, Solomos Solomouo and Melvyn Weeks. 


\section{Introduction}

The issue of whether per capita output of different countries or regions have been converging or are likely to converge in the future has played a central role in the recent empirical growth literature as well as in the debates surrounding European integration and its sustainability ${ }^{1}$ In the growth literature the notion of convergence has been used in a number of different contexts. The so called beta-convergence considers the speed with which output (measured by logarithm of per capita Gross Domestic Product) of a given country (region) converges over time to its steady state (evolving equilibrium) value. This notion refers to convergence within an economy and is only loosely related to the problem of output convergence across countries. Even if the analysis of convergence is confined to the evolution of a given economy over time, beta-convergence as motivated in the literature by Barro and Sala-i-Martin (1995), pre-assumes a deterministic growth process and as demonstrated by Binder and Pesaran (1999) can be inappropriate if the process of technological progress is in fact stochastic. For example, in the case where shocks to technology follow a random walk process, per capita output will fail the beta-convergence test even though the underlying stochastic process of the economy is convergent and ergodic. Therefore, beta-convergence is not a useful concept either for the analysis of output convergence within a given economy or for the analysis of cross-country output convergence once the stochastic nature of the technological process is taken into account. Another important empirical implication being that unit root tests applied to per capita output series either individually or in their panel forms are not informative about within or cross country convergence, either. Since it is not possible to rule out a unit root in the process of technological process on a priori grounds, testing for unit roots in per capita output will not be much help in shedding light on the problem of within country convergence. See Lee, Pesaran and Smith $(1997,1998)$ for further analysis and an empirical investigation.

However, formal tests of cross-country convergence can be developed by focussing on pair-wise output gaps (or output deviations), irrespective of whether the technological process is deterministic, stochastic, and/or contains a random walk component. Bernard and Durlauf $(1995,1996)$ were the first to define cross-country output convergence in terms of the limit of expected output gaps which allow for the possibility of unit roots in per capita outputs. Based on this definition they propose testing for cross-country convergence using cointegration techniques. In their empirical application they consider output series from 15 OECD countries over the period 1900-1987 and apply multivariate cointegration techniques to all the 15 series, a subset of 11 European series and a smaller subset of 6 European series. The cointegration tests are applied to all the individual output series as well as to output deviations computed with respect to the US output for the 15 OECD sample, and with respect to French output for

\footnotetext{
${ }^{1}$ For excellent surveys of empirical growth literature see Durlauf and Quah (1999), Temple (1999), and Islam (2003).
} 
the two sub-samples. Overall, the convergence hypothesis is rejected.

The use of multivariate cointegration techniques to test for cross country convergence is limited as it can not be applied to more than a small subset of countries in the global economy. This is particularly so if one attempts to go beyond the set of 15 OECD countries studied by Bernard and Durlauf, or the G7 countries recently investigated by Luginbuhl and Koopman (2003) for which reliable long output series do not exist. Application of unit root tests to output gaps is more practical, but is not invariant to the choice of the benchmark country and as a result can lead to misleading conclusions.

In this paper we propose a probabilistic version of the output convergence concept which is valid generally, and does not require the converging economies to be identical in all respects (saving rates, population growths and initial endowments). We derive necessary and sufficient conditions for cross country output convergence, and in particular show that for two countries to be convergent it is necessary that their output gap is stationary with a constant mean. This is valid irrespective of whether the individual country output series are trend stationary and/or contain unit roots. Therefore, cointegration is necessary for convergence but not sufficient if the underlying series are trend stationary. Convergence requires the output series to be co-trended, in addition to being cointegrated with the cointegrating vector of the form $(1,-1)$. To analyze output convergence across a large number of countries without being subject to the pitfalls that surround the use of output gaps measured relative to a particular country benchmark, we examine the unit-root and trending properties of all $N(N-1) / 2$ possible log real per capita output gaps, $y_{i t}-y_{j t}$, for $i=1, \ldots, N-1$, and $j=i+1, \ldots, N$. We also consider a number of average measures of log-output dispersions defined as simple or weighted averages of the absolute $(\log )$ output gap pairs, $\left|y_{i t}-y_{j t}\right|$ or their squares, $\left(y_{i t}-y_{j t}\right)^{2}$. We show that when abstracting from within country output differences, it is appropriate to weight the output gaps by relative population sizes. We also note that the use of absolute output gap pairs lead to the mean difference coefficient which is the numerator of the Gini coefficient. It is shown that under the null of (log) output convergence the output gaps, $y_{i t}-y_{j t}$, as well as the multi-country average measures of dispersions are stationary with a constant mean. We propose the use of pair-wise as well as multi-country measures of output dispersions in the analysis of output convergence. As compared to cross section or panel techniques used for the analysis of convergence, the pair-wise approach has the added advantage that it relates more naturally to the club convergence literature advanced in the literature by Durlauf and Johnson (1995), Quah (1996a, 1996b, 1997), Galor (1996) and examined further by Bianchi (1997), Hobijn and Franses (2000), Canova (2001) and many others. In principle, the convergence results from the analysis of pair-wise output gaps can be used to form "convergence clubs", but special care must be taken in dealing with the specification search bias that such a strategy would entail.

The pair-wise approach and the multi-country measures are applied to the output series in the Penn World Tables over the 1950-2000 period, as well as to Maddison's historical series now available over the period 1870-2000 for 17 
advanced economies. Overall, the results do not support the output convergence hypothesis. For example, using PWT data over the period 1961-2000, the unit root hypothesis was rejected at most in the case of 370 out of 4851 possible output gap pairs, just around $7.6 \%$, which is very close to the nominal significance level of $5 \%$ used for the test. The 370 outcomes, although seemingly large in absolute numbers, could have arisen out of pure chance. The evidence is slightly more favourable to output convergence if the null hypothesis being tested is stationarity rather than unit root, or when the Maddison data is used. Nevertheless, overall the results do not support the output convergence hypothesis and suggest that the identification of club convergence by some investigators might be due to pure chance, not to mention the usual sample selection biases associated with statistical grouping procedures often used in the literature. Furthermore, even if one accepts that such convergence clubs exist, their membership tends to undergo important changes over time. The main reason for this non-convergent result seems to be the existence of countryspecific unobserved factors that tend to be highly persistent. However, at the same time we find significant evidence of growth convergence, a result which is reasonably robust to the choice of the sample period and country groupings. Non-convergence of log per capita outputs combined with growth convergence suggests that while common technological progress seems to have been diffusing reasonably widely across economies, there are nevertheless important countryspecific factors (for example, wars, famines, revolutions, regime and institutional changes) that render output gaps highly persistent, such that we cannot be sure that the probability for the output gaps to lie within a fixed range will be non-zero.

The plan of the paper is as follows. Sections 2 reviews the implications of the stochastic Slow growth model for cross country output convergence. Section 3 proposes a probabilistic definition of pair-wise output convergence. Section 4 considers the issue of multi-country convergence. Tests of pair-wise output convergence are discussed in Section 5, and the multi-country average measures are set out in Section 6. Empirical evidence on output and growth convergence are discussed in Sections 7 and 8, respectively. Some concluding remarks are provided in Section 9.

\section{The Neoclassical Growth Model and Conver- gence}

It is important that the analysis of output convergence is carried out with respect to an appropriate theoretical framework. The growth model often used for this purpose is the deterministic version of the Solow-Swan model. See, for example, Barro and Sala-i-Martin (1995), Mankiw, Romer and Weil (1992) and Islam (1995). However, as argued in Binder and Pesaran (1999) and Lee, Pesaran and Smith (1997), the use of the deterministic version in empirical research can lead to misleading conclusions. For example, presence of a unit 
root in the output process might wrongly be interpreted as evidence against the neoclassical growth model, whilst as we shall see below such an outcome is perfectly compatible with a stochastic version of the neoclassical growth model that allows the technological process to have a unit root.

Following Lee, Pesaran and Smith (LPS) suppose that real output of country $i$ at time $t, Y_{i t}$, is produced by the Cobb-Douglas production function

$$
Y_{i t}=K_{i t}^{\alpha}\left(A_{i t} L_{i t}\right)^{1-\alpha}, 0<\alpha<1
$$

with

$$
\begin{gathered}
K_{i t}=I_{i, t-1}+(1-\delta) K_{i, t-1}, \\
I_{i t}=s_{i} Y_{i t},
\end{gathered}
$$

where $K_{i t}$ is the physical capital, $L_{i t}$ the number of workers employed, $A_{i t}$ the level technological progress. It is assumed that all countries have access to the same production function ( $\alpha$ is the same across countries) and are subject to the same rate of capital depreciation, $\delta$. However, they might differ in technological and labour force endowments, and their saving rate, $s_{i}$, assumed fixed. Technology and employment are assumed to evolve in a stochastic manner:

$$
\begin{gathered}
a_{i t}=\ln \left(A_{i t}\right)=\bar{a}_{i 0}+g_{i} t+u_{i t}, \\
l_{i t}=\ln \left(L_{i t}\right)=\bar{l}_{i 0}+n_{i} t+v_{i t},
\end{gathered}
$$

where $\bar{a}_{i 0}=E\left(a_{i 0}\right), \bar{l}_{i 0}=E\left(l_{i 0}\right)$ are assumed fixed, $g_{i}$ and $n_{i}$ are the steady state growth rates of technology and employment, and $u_{i t}$ and $v_{i t}$ are the stochastic components of technology and employment. In what follows we assume that $u_{i t}$ and $v_{i t}$ are general integrated processes of orders at most equal to unity, $I(1)$, such that $\Delta\left(u_{i t}+v_{i t}\right)$ is strictly stationary and ergodic.

In terms of capital per effective labour units, $k_{i t}=K_{i t} / A_{i t} L_{i t}$ we have

$$
\Delta \ln \left(k_{i t}\right)=-\left(g_{i}+n_{i}\right)-\Delta\left(u_{i t}+v_{i t}\right)+\ln \left(s_{i} k_{i, t-1}^{-(1-\alpha)}+1-\delta\right) .
$$

Under certain assumptions on $u_{i t}+v_{i t}$, and assuming that $0<\alpha, \delta<1$, Binder and Pesaran (1999) show that $k_{i t}$ converges to a time-invariant distribution for each $i$. As a result $y_{i t}=\log \left(Y_{i t} / L_{i t}\right)$ also converges to a steady state distribution, whose evolution is given by

$$
y_{i t}=a_{i t}+\alpha \ln \left(k_{i t}\right),
$$

and $y_{i t}$ will be having the same limiting time series properties as $a_{i t}$. For example, $y_{i t}$ will have a unit root if and only if $a_{i t}$ has a unit root. Based on the derivations in LPS, a log-linearized solution for $y_{i t}$ is given by

$$
\begin{gathered}
y_{i t}=c_{i}+g_{i} t+u_{i t}+\eta_{i t} \\
c_{i}=\bar{a}_{i 0}+\frac{\alpha\left[\gamma_{i}-n_{i}-g_{i}\right]}{1-\lambda_{i}},
\end{gathered}
$$




$$
\eta_{i t}=-\alpha \sum_{j=0}^{\infty}\left(1-\lambda_{i}\right)^{j}\left(\Delta u_{i, t-j}+\Delta v_{i, t-j}\right),
$$

and the parameters $\gamma_{i}$ and $\lambda_{i}$ are related to the structural coefficients through the following approximate relations

$$
\begin{aligned}
& \lambda_{i} \approx 1-(1-\delta)\left(n_{i}+g_{i}+\delta-h_{i}\right), 0<\lambda_{i}<1, \\
& \gamma_{i} \approx\left(n_{i}+g_{i}-h_{i}\right)+\left(n_{i}+g_{i}+\delta+h_{i}\right)\left[\ln \left(s_{i}\right)-\ln \left(n_{i}+g_{i}+\delta-h_{i}\right)\right],
\end{aligned}
$$

where

$$
h_{i}=n_{i}+g_{i}-\ln \left\{s_{i} e^{-(1-\alpha) E\left[\ln \left(k_{i, \infty}\right)\right]}+1-\delta\right\},
$$

and $k_{i, \infty}$ denotes the limit of $k_{i t}$ as $t \rightarrow \infty$.

Equation (3) provides a convenient decomposition of log per capita output into a fixed effect, $c_{i}$, a deterministic trend component, $g_{i} t$, and two stochastic components, $u_{i t}$ and $\xi_{i t}$ defined by (4) and (5). This decomposition helps clarify a number of important issues in the analysis of within and cross country output convergence.

1. There is an asymmetry in the way supply and demand shocks affect output per capita. Whilst a unit root in technology results in a unit root in per capita output, the same is not true of employment process. A unit root in employment demand does not cause per capita output to be a unit root process.

2. In general, the stochastic version of the neoclassical growth model is compatible with per capita output being a trend-stationary or a unit root process. Therefore, presence of a unit root in per capita output by itself does not provide evidence against the theory.

3. Although the neoclassical theory (in its deterministic or stochastic forms) does not explicitly address the issue of cross-country output convergence, it could be argued that in an inter-related global economy technology will inevitably be diffused across economies either directly or through trade in investment goods, and it is therefore unlikely that $g_{i} t$ and $u_{i t}$ (the deterministic and stochastic components of technology) could differ across countries in a systematic manner. To capture the idea that all economies have access, possibly with different degrees, to the same pool of technological knowledge we write $u_{i t}$ as the following multi-factor model

$$
u_{i t}=\boldsymbol{\theta}_{i}^{\prime} \mathbf{f}_{t}+\varepsilon_{i t},
$$

where $\mathbf{f}_{t}$ is the $m \times 1$ vector common components, $\boldsymbol{\theta}_{i}$ are the associated vector of factor loadings and $\varepsilon_{i t}$ is the idiosyncratic component, assumed to be specific to country $i$. More complicated multi-factor models can also be considered, but they add little to our analysis and will not be attempted here. In principle, both components, $\mathbf{f}_{t}$ and $\varepsilon_{i t}$ could contain unit roots. But as we shall see below for cross country output convergence 
it is necessary (although by no means sufficient) that the idiosyncratic components, $\varepsilon_{i t}$, are stationary. Without any loss of generality we shall assume that $\mathbf{f}_{t}$ and $\varepsilon_{i t}$ are independently distributed with zero means.

4. Due to the strong possibility that $y_{i t}$ process might contain a unit root through a unit root in $u_{i t}$, empirical analysis of within-country convergence is best carried out in terms of output growth, $g_{i t}=\Delta y_{i t}$, rather than levels of per capita output, $y_{i t}$. Using (3) and (5) we have

$$
g_{i t}=g_{i}+\Delta u_{i t}-\alpha\left(\frac{1}{1-\beta_{i} L}\right)\left(\Delta^{2} u_{i t}+\Delta^{2} v_{i t}\right),
$$

where $L$ is a back-ward lag operator, and $\beta_{i}=1-\lambda_{i}$, which leads to the following dynamic equation in growth rates:

$$
g_{i t}=\left(1-\beta_{i}\right) g_{i}+\beta_{i} g_{i, t-1}+(1-\alpha) \Delta u_{i t}+\left(\alpha-\beta_{i}\right) \Delta u_{i, t-1}-\alpha \Delta^{2} v_{i t} .
$$

Since $\Delta u_{i t}$ and $\Delta v_{i t}$ are stationary irrespective of whether $u_{i t}$ and/or $v_{i t}$ have unit roots, the growth process is stationary and ergodic and can be analyzed by standard time series techniques. Equation (10) could also be used to identify the relative quantitative importance of demand and supply shocks on output growth by augmenting it with equations for employment demand and technological innovations using direct measures such as patent or R\&D time series data.

We now turn our attention to the issue of cross-country convergence, which is our primary focus in this paper.

\section{Cross-Country Output Convergence}

Consider the problem of output convergence in a sample of $N$ countries, and suppose that the logarithm of real per capita output of country $i$ at time, $y_{i t}$, for $i=1,2, \ldots, N$, satisfies the decomposition (3) with $u_{i t}$ given by the multi-factor model (8), namely

$$
y_{i t}=c_{i}+g_{i} t+\boldsymbol{\theta}_{i}^{\prime} \mathbf{f}_{t}+\varepsilon_{i t}+\eta_{i t}, \text { for } i=1,2, \ldots, N \text {. }
$$

According to Bernard and Durlauf's Definition 2.1, countries $i$ and $j$ converge if

$$
\lim _{k \rightarrow \infty} E\left(y_{i, t+k}-y_{j, t+k} \mid \mathcal{I}_{t}\right)=0 \text {, at any fixed time } t,
$$

where $\mathcal{I}_{t}$ is the information set at time $t$, which contains at least the current and past output series $y_{i, t-s}$, for $i=1,2, \ldots, n$ and $s=0,1,2, \ldots$. Based on this definition Bernard and Durlauf (BD) state that for countries $i$ and $j$ to converge it is necessary that their outputs are cointegrated with cointegrating vector $(1,-1)$. However, as we shall demonstrate below cointegration is not sufficient for (12) to hold. 
Making use of the output processes in (11) we have

$$
\begin{array}{rll}
E\left(y_{i, t+k}-y_{j, t+k} \mid \mathcal{I}_{t}\right) & =\left(c_{i}-c_{j}\right)+\left(g_{i}-g_{j}\right)(t+k)+\left(\boldsymbol{\theta}_{i}-\boldsymbol{\theta}_{j}\right)^{\prime} E\left(\mathbf{f}_{t+k} \mid \mathcal{I}_{t}\right) \\
+E\left(\varepsilon_{i, t+k}-\varepsilon_{j, t+k}\right. & \mid & \left.\mathcal{I}_{t}\right)+E\left(\eta_{i, t+k}-\eta_{j, t+k} \mid \mathcal{I}_{t}\right) .
\end{array}
$$

Under our assumptions $\eta_{i, t+k}-\eta_{j, t+k}$ is a stationary process, irrespective of whether the technology and demand shocks are $I(1)$ or $I(0)$. Hence

$$
\lim _{k \rightarrow \infty} E\left(\eta_{i, t+k}-\eta_{j, t+k} \mid \mathcal{I}_{t}\right)=E\left(\eta_{i t}-\eta_{j t}\right)=0 .
$$

Also the case where the idiosyncratic component of $u_{i t}$, namely $\varepsilon_{i t}$ is $I(1)$ can be ruled out, since in that case $\lim _{k \rightarrow \infty} E\left(\varepsilon_{i, t+k}-\varepsilon_{j, t+k} \mid \mathcal{I}_{t}\right) \neq 0$.

Consider now the two remaining cases where $\boldsymbol{\theta}_{i}^{\prime} \mathbf{f}_{t} \sim I(0)$ or $\boldsymbol{\theta}_{i}^{\prime} \mathbf{f}_{t} \sim I(1)$. Under the former countries $i$ and $j$ converge in the sense of $\mathrm{BD}$, if ${ }^{2}$

$$
c_{i}=c_{j},
$$

and

$$
g_{i}=g_{j} .
$$

Under $\boldsymbol{\theta}_{i}^{\prime} \mathbf{f}_{t} \sim I(1)$ in addition to the above conditions it is also required that ${ }^{3}$

$$
\boldsymbol{\theta}_{i}=\boldsymbol{\theta}_{j} .
$$

Out of the above three conditions the first, $c_{i}=c_{j}$, is the most unlikely to be satisfied as it requires the two economies to be identical almost in every respects, including their saving rates and initial endowments. See (4). A less stringent definition of convergence can be formulated in terms of the (conditional) probability of the output gap, $y_{i t}-y_{j t}$, falling outside a pre-defined interval.

Definition 1 (Pair-wise Convergence) Countries $i$ and $j$ converge if for some finite positive constant $C$, and a tolerance probability measure $\pi \geq 0$,

$$
\operatorname{Pr}\left\{\left|y_{i, t+s}-y_{j, t+s}\right|<C \mid \mathcal{I}_{t}\right\}>\pi,
$$

at all horizons, $s=1,2, \ldots, \infty$.

Applied to (11), this definition clearly rules out deterministic as well as stochastic trends in the output gap process. Unless (15) and (16) are both satisfied, it is easily seen that

$$
\lim _{k \rightarrow \infty} \operatorname{Pr}\left\{\left|y_{i, t+k}-y_{j, t+k}\right|<C \mid \mathcal{I}_{t}\right\}=0,
$$

\footnotetext{
${ }^{2}$ For an elaboration of Bernard and Durlauf's definitions also see Hobijn and Franses (2000, pp. 61-62).

${ }^{3}$ Intermediate cases could also arise where the $m \times 1$ vector of common factors, $\mathbf{f}_{t}$ are $I$ (1) but admit $r$ cointegrating relations with $r<m$. However, we would still have the two possibilities considered, namely $\boldsymbol{\theta}_{i}^{\prime} \mathbf{f}_{t}$ could either be $I(0)$ or $I(1)$, depending on whether all the country-specific factor loadings lie in the cointegrating space of $\mathbf{f}_{t}$. These considerations complicate the analysis without adding much substance to our arguments or results and will not be pursued further.
} 
for all finite positive constants, $C$, and the output gap diverges. However, it is important to note that the above probabilistic definition does not necessarily require that $c_{i}=c_{j}$. Therefore, it allows convergent economies to have different endowments, saving rates or population growth rates.

In a cointegrating framework, the conditions (15) and (16) are in fact the familiar cointegrating and co-trending restrictions, respectively. ${ }^{4}$ The former is relevant only if it is known that the underlying output processes, $y_{i t}$ and $y_{j t}$ are both $I(1)$. In practice, the cointegration approach would involve certain degree of pre-testing as the individual output series are first tested for unit roots. However, the pre-testing problem can be avoided by directly testing the output gap, $y_{i t}-y_{j t}$, for the absence of unit roots and linear deterministic trends.

Under (15) and (16), the output gap is stationary with mean $c_{i}-c_{j}$ and

$\lim _{s \rightarrow \infty} \operatorname{Pr}\left\{\left|y_{i, t+s}-y_{j, t+s}\right|<C \mid \mathcal{I}_{t}\right\}=\operatorname{Pr}\left\{-C-\left(c_{i}-c_{j}\right)<\psi_{i j t}<C-\left(c_{i}-c_{j}\right)\right\}$,

where

$$
\psi_{i j t}=\varepsilon_{i t}-\varepsilon_{j t}+\eta_{i t}-\eta_{j t} .
$$

Denoting the variance of $\psi_{i j t}$ by $\omega_{i j}^{2}$, and for illustrative purposes assuming that the shocks are normally distributed we have

$$
\begin{aligned}
\lim _{s \rightarrow \infty} \operatorname{Pr}\left\{\left|y_{i, t+s}-y_{j, t+s}\right|<C \mid \mathcal{I}_{t}\right\} & =\Phi\left(\frac{C-\left(c_{i}-c_{j}\right)}{\omega_{i j}}\right)-\Phi\left(\frac{-C-\left(c_{i}-c_{j}\right)}{\omega_{i j}}\right) \\
& =\Phi\left(\frac{C-\left(c_{i}-c_{j}\right)}{\omega_{i j}}\right)+\Phi\left(\frac{C+\left(c_{i}-c_{j}\right)}{\omega_{i j}}\right)-1,
\end{aligned}
$$

where $\Phi($.$) is the cumulative distribution function of the standard normal vari-$ able. Therefore,

$$
\lim _{s \rightarrow \infty} \operatorname{Pr}\left\{\left|y_{i, t+s}-y_{j, t+s}\right|<C \mid \mathcal{I}_{t}\right\}>0,
$$

so long as $C>\left|c_{i}-c_{j}\right| .{ }^{5}$ It is clear that our notion of convergence does allow for the two countries to have different initial endowments, saving rates or rates of population growths.

\section{Multi-country Convergence}

So far we have focussed on tests of output convergence applied to two countries. The extension to more countries pose new technical difficulties. For two countries testing for convergence is relatively simple and can be carried out by testing the hypothesis that the output gap, $y_{i t}-y_{j t}$, is stationary with a fixed mean. Also as noted earlier such a test has the additional advantage that it does not require pre-testing for the presence of unit roots in the individual output series. In a multi-country setting two approaches have been advanced in the literature by Bernard and Durlauf (1995) and followed by many others. ${ }^{6}$ One

\footnotetext{
${ }^{4}$ For a detailed discussion of co-trending restrictions in a multivariate cointegrating framework see, for example, Pesaran, Smith and Shin (2000).

${ }^{5}$ Recall that $\Phi(a) \geq 1 / 2$ for $a \geq 0$.

${ }^{6}$ See, for example, Oxley and Greasley (1995), and Camarero, Flôres and Tamarit (2002).
} 
approach assumes (often with pre-testing) that the individual output series. $y_{i t}$, $i=1,2, \ldots, N$ are $I(1)$ and applies the system cointegrating techniques directly to these series and tests for the existence of $N-1$ cointegrating vectors of the form $(1,-1)$ amongst these $N$ series. As our theoretical analysis shows, under this approach it is important that the underlying model allows for the possibility of deterministic trends, with the cointegrating relations (if any) tested for co-trending. The appropriate null hypothesis for multicounty convergence is the simultaneous existence of $N-1$ cointegrating and co-trending relations of the form $(1,-1)$. A second procedure considers testing for unit roots in $N-1$ output gaps measured with respect to a benchmark country. Using country 1 (for example) as the benchmark the output gaps $y_{i t}-y_{1 t}$ for $i=2,3, \ldots, N$ are tested for unit roots. Once again this is not sufficient and one also needs to test that the output gaps do not contain deterministic trends. This procedure is simpler to implement and has the advantage that it does not involve pre-testing of the individual series for unit roots. However, it is dependent on the choice of the benchmark country and could yield misleading results. For example, in a three country setting with country 1 used as the benchmark, countries 2 and 3 could be convergent even if the output gaps, $y_{2 t}-y_{1 t}$ and $y_{3 t}-y_{1 t}$ are divergent, namely contain unit roots and/or deterministic trends. In terms of conditions (15) and (16), this case could arise if

$$
g_{2}=g_{3}, g_{2} \neq g_{1} \text {, and } / \text { or } \boldsymbol{\theta}_{2}=\boldsymbol{\theta}_{3}, \boldsymbol{\theta}_{2} \neq \boldsymbol{\theta}_{1} \text {. }
$$

For analysis of multi-country convergence all country combinations must be considered. Accordingly, we suggest the following definition:

Definition 2 (Multi-country Convergence) Countries $i=1,2, \ldots, N$ are said to converge if for some finite positive constant $C$, and a tolerance probability measure $\pi \geq 0$,

$$
\operatorname{Pr}\left\{\cap_{i=1, \ldots, N-1, j=i+1, \ldots, N}\left|y_{i, t+s}-y_{j, t+s}\right|<C \mid \mathcal{I}_{t}\right\}>\pi,
$$

at all horizons, $s=1,2, \ldots, \infty$.

Therefore, what is required for multi-country convergence is pair-wise convergence across all country combinations. The system cointegrating approach accommodates this definition of multi-country convergence, since it considers all linear combinations of individual output series and hence all linear combinations of pair-wise output gaps. However, its scope is limited in practice as it can efficiently handle only a small number of countries simultaneously. As a result many investigators have confined the application of the system approach to a handful of countries. Bernard and Durlauf using a relatively large span of time series covering the period 1900-1987 consider a maximum number of 15 countries in their empirical investigation. ${ }^{7}$ In their analysis Oxley and Greasley (1995), Camarero et al. (2002) consider 3 and 7 countries, respectively. None

\footnotetext{
${ }^{7}$ Use of long time series could increase the likelihood of structural breaks in the underlying processes that could bias the results of the cointegration analysis.
} 
of these studies allow for deterministic trends and therefore do not consider the possibility that output series that cointegrate might not be co-trending.

To be able to analyze the convergence properties of a large number of countries, whilst at the same time avoiding the pitfalls that surround the use of a given benchmark, in this paper we consider two approaches: a pair-wise approach that considers the unit-root and trending properties of all $N(N-1) / 2$ possible output gaps, $y_{i t}-y_{j t}$, for $i=1, \ldots, N-1$, and $j=i+1, \ldots, N$, and a multivariate approach which aims at providing an overall index of output convergence. The pair-wise approach is likely to be more informative for investigating the hypothesis of "club convergence" advanced in the literature by Quah (1996a,1996b, 1997), and allows for the possibility of forming country clusters (if any) from the test outcomes.

\section{Tests of Pair-wise Output Convergence}

Consider any two countries, $i$ and $j$, and denote their log per-capita output gap by $y_{i t}-y_{j t}$. According to our definition, these two countries are (output) convergent if $y_{i t}-y_{j t}$ is an $I(0)$ process with a constant mean. Accordingly, for each $i$ and $j$ we adopt a sequential procedure where in the first stage $d_{i j t}=$ $y_{i t}-y_{j t}$ is tested for unit roots using augmented Dickey-Fuller (ADF) regressions with an intercept and a linear trend:

$$
\Delta d_{i j t}=a_{j i}+\beta_{i j}\left(g_{i}-g_{j}\right) t+\beta_{i j} d_{i j, t-1}+\sum_{s=1}^{p_{i j}} \delta_{i j s} \Delta d_{i j, t-s}+\nu_{j i t},
$$

The order of the $A D F$ regressions, $p_{i j}$, can be chosen using model selection criteria such as the Akaike Information Criterion (AIC). In our empirical applications we report test results for $p_{i j}=1,2,3$ and 4 , as well as for the AIC selected augmentation orders. If the unit root hypothesis is rejected we then consider testing the hypothesis that $g_{i}=g_{j}$, namely $y_{i t}-y_{j t}$ is not trended.

An alternative approach would be to take the "stationarity" as the null hypothesis, and use the test developed by Kwiatkowski, Phillips, Schmidt and Shin (KPSS, 1992). The test is based on the idea that the variance of the partial sum series

$$
s_{i j t}=\sum_{\ell=1}^{t} \widehat{e}_{i j \ell}, \text { where } \widehat{e}_{i j \ell}=\left(d_{i j \ell}-\bar{d}_{i j}\right), \bar{d}_{i j}=T^{-1} \sum_{\ell=1}^{T} d_{i j \ell},
$$

would be relatively small under stationarity as compared to the non-stationary unit root hypothesis. The KPSS test statistic is defined by

$$
\operatorname{KPSS}_{i j T}(\ell)=\frac{T^{-2} \sum_{t=1}^{T} s_{i j t}^{2}}{s_{i j T}^{2}(\ell)}
$$


where $s_{i j T}^{2}(\ell)$ is the estimate of the long-run variance of $s_{t}$, given by

$$
s_{i j T}^{2}(\ell)=\frac{1}{T} \sum_{t=1}^{T} \widehat{e}_{t}^{2}+\frac{2}{T}\left[\sum_{k=1}^{\ell} w_{k}\left(\sum_{t=k+1}^{T} \widehat{e}_{i j t} \widehat{e}_{i j t-k}\right)\right],
$$

$\ell$, is the lag window often approximated by $0.75 T^{1 / 3}$, and

$$
w_{k}=1-\frac{k}{\ell+1}, \quad k=1,2, \ldots, \ell
$$

Both tests would be applied to all output pairs, namely a total of $N(N-1) / 2$ tests would be carried out and the results summarized by different regions. Although, the test outcomes across the different output pairs are clearly dependent, the proportion of output pairs that meet the stationarity conditions can still be estimated consistently for $N$ sufficiently large. However, the outcome of pair-wise tests could be contradictory. Consider, for example, the two output gaps, $y_{1 t}-y_{2 t}$ and $y_{1 t}-y_{3 t}$ and suppose that by application of the KPSS test (or the two-stage ADF based test discussed above) to these output gaps it is concluded that $y_{1 t}-y_{2 t}$ and $y_{1 t}-y_{3 t}$ are both stationary with constant means. It would then follow logically that the output gap, $y_{2 t}-y_{3 t}$ should also be stationary with a constant mean. But, in small samples there is no guarantee that if the KPSS or the ADF tests are applied to $y_{2 t}-y_{3 t}$ the outcome would necessarily be stationary. Such occurrences should be viewed as an implication of the low power of testing for unit roots or stationarity, and not a logical defect of the pair-wise procedure.

\section{Average Measures of Convergence/Divergence}

It is also possible to construct "average" measures of convergence/divergence using the output gaps, $y_{i t}-y_{j t}, i=1, . ., N-1, j=i+1, \ldots, N$. The squares or absolute values of the output gaps can be averaged across country pairs as simple or weighted averages.

\subsection{Unweighted Measures of Dispersions}

Using squares and a simple average we have

$$
D_{t}^{2}=\frac{2}{N(N-1)} \sum_{i=1}^{N-1} \sum_{j=i+1}^{N}\left(y_{i t}-y_{j t}\right)^{2},
$$

But since

$$
\sum_{i=1}^{N-1} \sum_{j=i+1}^{N}\left(y_{i t}-y_{j t}\right)^{2}=(1 / 2) \sum_{i=1}^{N} \sum_{j=1}^{N}\left(y_{i t}-y_{j t}\right)^{2}
$$


it is easily seen that

$$
\begin{aligned}
D_{t}^{2} & =\frac{1}{N(N-1)} \sum_{i=1}^{N} \sum_{j=1}^{N}\left[\left(y_{i t}-\bar{y}_{t}\right)-\left(y_{j t}-\bar{y}_{t}\right)\right]^{2} \\
& =2\left\{\frac{\sum_{i=1}^{N}\left(y_{i t}-\bar{y}_{t}\right)^{2}}{N-1}\right\}=2 s_{t}^{2},
\end{aligned}
$$

where $\bar{y}_{t}=N^{-1} \sum_{j=1}^{N} y_{i t}$. Namely, $D_{t}$ is proportional to the cross section standard deviation of $y_{i t}$ across $i$, used extensively in the literature to examine the cross country output convergence referred to as " $\sigma$ convergence". Derivation of $s_{t}$ from a simple average of output gaps allows us to link it to the underlying log-linearlized solution of the stochastic Solow model given by (3) and (11). Under the null hypothesis that countries $i$ and $j$ converge we must have

$$
y_{i t}-y_{j t}=c_{i}-c_{j}+\varepsilon_{i t}-\varepsilon_{j t}+\eta_{i t}-\eta_{j t},
$$

where $c_{i}$ is a fixed constant defined by (4) and $\varepsilon_{i t}-\varepsilon_{j t}+\eta_{i t}-\eta_{j t}$ is a stationary process with mean zero and variance $\omega_{i j}^{2}$. Therefore, under the null hypothesis

$$
E\left(s_{t}^{2}\right)=\frac{1}{N(N-1)} \sum_{i=1}^{N-1} \sum_{j=i+1}^{N}\left(c_{i}-c_{j}\right)^{2}+\frac{1}{N(N-1)} \sum_{i=1}^{N-1} \sum_{j=i+1}^{N} \omega_{i j}^{2},
$$

which does not vary with time. In contrast, $E\left(s_{t}^{2}\right)$ will be trended upward if output diverges across two or more countries. As an illustration consider (11), and suppose that $\boldsymbol{\theta}_{i}=\boldsymbol{\theta}_{j}$ but allow $g_{i} \neq g_{j}$. In this case we have

$$
\begin{aligned}
E\left(s_{t}^{2}\right)= & \frac{1}{N(N-1)} \sum_{i=1}^{N-1} \sum_{j=i+1}^{N}\left(c_{i}-c_{j}\right)^{2}+\frac{2 t}{N(N-1)} \sum_{i=1}^{N-1} \sum_{j=i+1}^{N}\left(c_{i}-c_{j}\right)\left(g_{i}-g_{j}\right) \\
& +\frac{t^{2}}{N(N-1)} \sum_{i=1}^{N-1} \sum_{j=i+1}^{N}\left(g_{i}-g_{j}\right)^{2}+\frac{1}{N(N-1)} \sum_{i=1}^{N-1} \sum_{j=i+1}^{N} \omega_{i j}^{2},
\end{aligned}
$$

which is dominated by a quadratic trend, the size of which depends on the dispersion of growth rates as measured by $\sum_{i=1}^{N-1} \sum_{j=i+1}^{N}\left(g_{i}-g_{j}\right)^{2} / N(N-1)=$ $\sum_{i=1}^{N}\left(g_{i}-\bar{g}\right)^{2} /(N-1)$. A similar result obtains if $g_{i}=g_{j}$, but $\boldsymbol{\theta}_{i} \neq \boldsymbol{\theta}_{j}$ with $\boldsymbol{\theta}_{i}^{\prime} \mathbf{f}_{t} \sim I(1)$, although in this case the dominant trend in $E\left(s_{t}^{2}\right)$ will be linear.

The above analysis provides a theoretical justification for using $s_{t}$ as an overall measure of convergence. It further shows that a sustained trend in $s_{t}^{2}$ is not compatible with cross country output convergence. Similar conclusions can also be reached using other overall measures of dispersion. One particularly important measure would be to use the simple average of the absolute output gaps as given by

$$
\Delta_{t}=\frac{2}{N(N-1)} \sum_{i=1}^{N-1} \sum_{j=i+1}^{N}\left|y_{i t}-y_{j t}\right|
$$


This is known as the "mean difference" coefficient and forms the numerator of the well known Gini coefficient. The mean difference measure, $\Delta_{t}$, has certain theoretical attractions, although it is more difficult to compute and analyze as compared to $s_{t}^{2}$. Our interest in using it lies in the fact that it provides a link between the regression approaches to convergence and the cross-country analysis of distribution dynamics advocated by Quah (1996b). Like $E\left(s_{t}\right)$, the expected value of the mean difference coefficient, $E\left(\Delta_{t}\right)$, will be time invariant under the null hypothesis of pair-wise convergence. An exact expression for $E\left(\Delta_{t}\right)$, can be obtained if it is further assumed that $y_{i t}-y_{j t}$ is also normally distributed. Under this assumption we have

$$
E\left|y_{i t}-y_{j t}\right|=\omega_{i j}\left(\sqrt{\frac{2}{\pi}}\right) e^{(-1 / 2)\left(\frac{c_{i}-c_{j}}{\omega_{i j}}\right)^{2}}+\left|c_{i}-c_{j}\right|\left\{2 \Phi\left(\frac{c_{i}-c_{j}}{\omega_{i j}}\right)-1\right\},
$$

where $\Phi($.$) is the cumulative distribution function of a standard normal variate.$

It is also worth noting that due to the possible presence of unit roots and/or deterministic trends in $y_{i t}$, and hence in $\bar{y}_{t}$, the Gini coefficient defined by $G_{t}=\Delta_{t} / \bar{y}_{t}$, could display downward trends even under output convergence. ${ }^{8}$ Clearly, $\Delta_{t}$ is a more appropriate measure of the evolution of cross-country output convergence as compared to its scaled version, $G_{t}$. It also relates directly to the pair-wise output gaps that underlie a multivariate analysis of convergence.

\subsection{Weighted Measures of Dispersions}

The two dispersion measures, $s_{t}$ and $\Delta_{t}$, discussed so far attach equal weights to all pairs of output gaps and might yield a misleading results when applied to countries with very different population sizes. Denote the population of country $i$ at time $t$ by $P_{i t}$, and abstract from within country income disparities. A population weighted measure of output-gap between countries $i$ and $j$ is given by $P_{i t} P_{j t}\left|y_{i t}-y_{j t}\right|$, and the population weighted counterparts of $D_{t}$ and $\Delta_{t}$ may be defined as

$$
D_{t}^{* 2}=\frac{\sum_{i=1}^{N-1} \sum_{j=i+1}^{N} P_{i t} P_{j t}\left(y_{i t}-y_{j t}\right)^{2}}{\sum_{i=1}^{N-1} \sum_{j=i+1}^{N} P_{i t} P_{j t}}
$$

and

$$
\Delta_{t}^{*}=\frac{\sum_{i=1}^{N-1} \sum_{j=i+1}^{N} P_{i t} P_{j t}\left|y_{i t}-y_{j t}\right|}{\sum_{i=1}^{N-1} \sum_{j=i+1}^{N} P_{i t} P_{j t}}
$$

${ }^{8}$ Note that in the analysis of size distribution of income, Gini coefficient is usually applied to individual or household incomes and not to their logarithms as it is done here. But in the analysis of cross country output convergence, due to the preferred Cobb-Douglas form of the production function, the use of $\log$ per capita output is clearly more appropriate than the per capita outputs. 
It is easily verified that these weighted measures reduce to $D_{t}$ and $\Delta_{t}$ if $P_{i t}=P_{j t}$ for all $i$ and $j$. Since

$$
\sum_{i=1}^{N-1} \sum_{j=i+1}^{N} P_{i t} P_{j t}=\frac{1}{2}\left(P_{t}^{2}-\sum_{i=1}^{N} P_{i t}^{2}\right),
$$

where $P_{t}=\sum_{i=1}^{N} P_{i t}$, the above measures can also be written as

$$
D_{t}^{* 2}=\frac{2 \sum_{i=1}^{N} w_{i t}\left(y_{i t}-\bar{y}_{w t}\right)^{2}}{1-\sum_{i=1}^{N} w_{i t}^{2}},
$$

and

$$
\Delta_{t}^{*}=\frac{\sum_{i=1}^{N} \sum_{j=1}^{N} w_{i t} w_{j t}\left|y_{i t}-y_{j t}\right|}{1-\sum_{i=1}^{N} w_{i t}^{2}}
$$

$w_{i t}=P_{i t} / P_{t}$ is the share of $i^{t h}$ country population in the country grouping under consideration, and $\bar{y}_{w t}=\sum_{i=1}^{N} w_{i t} y_{i t}$. Accordingly, a population-weighted version of $s_{t}$ is given by

$$
s_{t}^{*}=\sqrt{1 / 2} D_{t}^{*}=\sqrt{\frac{\sum_{i=1}^{N} w_{i t}\left(y_{i t}-\bar{y}_{w t}\right)^{2}}{1-\sum_{i=1}^{N} w_{i t}^{2}}} .
$$

The trend properties of $E\left(\Delta_{t}^{*}\right)$ and $E\left(s_{t}^{*}\right)$ are the same as the ones obtained for their unweighted versions, under the assumption that the processes generating the population weights, $w_{i t}$, are stationary. However, in general the time profiles of $\Delta_{t}^{*}$ and $s_{t}^{*}$ would be influenced by output disparities as well as by the differences in population growths across countries.

\section{Empirical Evidence on Output Convergence}

Output convergence can be examined at global or regional levels. Since it is possible for some countries to be divergent within a given region but converge across regions, it is important that the investigation of output convergence starts at a global level. Primary sources of data for such an exercise are the annual output series from the Penn World Table (PWT) and the Maddison output series. In this study we use the Purchasing Power Parity adjusted Real GDP per capita in constant prices from the most recent Version 6.1 of PWT, and Maddison's (2003) latest per capita output series available from his home page (http://www.eco.rug.nl/\% 7EMaddison/). ${ }^{9}$ Both sets of data provide reasonably comparable measurements of per capita output across countries. ${ }^{10}$ The Maddison series has a much longer coverage, spanning the years 1870-2000, 1923-2000

\footnotetext{
${ }^{9}$ The PWT code for the series is RGDPL, and is constructed in international dollars, with 1996 as the reference year. For further details see Heston, Summers and Aten (2002).

${ }^{10}$ Some investigators using PWT series have also employed output per worker, arguing that it relates more closely to the underlying production processes. But we decided to focus on per capita output series that are more comparable across countries and relate more readily to the debate on trends on world income distribution.
} 
and 1900-2000 for advanced, South Europe and Latin American economies, respectively. The PWT series begin in 1951, but covers a wider set of countries, particularly if the start of the sample is brought forward to 1961. There is a trade off between the number of countries $(N)$ and the sample period $(T)$ used in the analysis. ${ }^{11}$ Accordingly, for the PWT data set we considered three sample periods: $1951-2000(T=50), 1961-2000(T=40)$ and 1971-200 $(T=30)$. The number of countries with a full set of output series across these periods turned out to be 56, 99, and 101, respectively. The lists of countries (by regions) for the Maddison and the PWT data sets are provided in Tables 1a and 1b. The time plot of the log per capita output series for the PWT data are displayed in Figures 1-6 (the "world" and five country groupings), and for Maddison's data set they are given in Figures 7-9. These figures show a wide variety of patterns, with different convergence/divergence episodes for different country groups.

\subsection{Evidence on Output Convergence Using PWT Series}

We begin by considering the unit root properties of all output gap pairs, $y_{i t}-y_{j t}$, in the world economy over the three periods $1951-2000(T=50, N=56)$, 1961$2000(T=40, N=99)$ and 1971-2000 $(T=30, N=101)$. The number of such output gap pairs over these three sample periods are 1540, 4851 and 5050, respectively. For each output gap series we compute three different unit root test statistics, namely the standard Augmented Dickey-Fuller statistic, $\operatorname{ADF}(\mathrm{p})$, the ADF-GLS(p) statistic proposed by Elliot et al. (1996) that makes use of more efficient estimates of deterministics, and the ADF weighted symmetric (ADFWS) test which is due to Park and Fuller (1995) and attempts to increase the power of the unit root test by making use of the fact that any stationary autoregressive process can be given a forward as well as a backward representation. ${ }^{12}$ The results for all the possible output gap pairs are summarized in Table 2, for the three sample periods. This table reports the proportions of the output gap pairs for which the unit root hypothesis is rejected at 10\% and 5\% significance levels, using the three unit root testing procedures set out above, and for different orders of augmentation, including the order selected using the Akaike Information Criterion (AIC). Although the test results are likely to be correlated across the different output gap pairs, the estimated proportions are nevertheless consistently estimated for $N$ sufficiently large. The results are uniformly against the convergence hypothesis. The proportion of the output gap pairs for which the unit root hypothesis is rejected matches the significance level of the $\mathrm{ADF}$ test, a result which is reasonably robust to the order of augmentation or the particular version of the ADF test being used. The rejection frequencies are slightly higher if the ADF-WS test is employed, possibly reflecting the higher

\footnotetext{
${ }^{11}$ Alternatively, one could use an unbalanced panel approach where the sample periods differ across a fixed maximum number of countries. Given the heterogeneous nature of the output processes across countries and the importance of the time series dimension for the performance of the tests that we shall be considering we decided not to follow this approach.

${ }^{12}$ Details of the computation of the ADF-GLS and the ADF-WS test statistics, together with their $5 \%$ and $10 \%$ critical values for the sample sizes considered in this paper are given in the Appendix.
} 
power of this test as compared to the other two versions of the test. ${ }^{13}$ The test results are also robust to the sample period being considered.

Conditioning on those output gap pairs for which the unit root hypothesis is rejected, the number of output gap pairs with insignificant (at the $5 \%$ level) linear trends are reported in Table 3 for the different sample periods and the ADF type tests. The numbers of output gap pairs that meet both criteria and can be viewed as being stationary with a constant mean are very small; and in no case exceed $3.8 \%$ of the total number of possible output gap pairs.

Very similar results are also obtained across different country groupings. The unit root test results for the five country groups are summarized in Table $4{ }^{14}$ Once again the ADF-WS test shows slightly higher rejection frequencies as compared with the other two tests. Nevertheless, the proportion of output gap pairs for which the unit root hypothesis is rejected is very close to the chosen significance levels for all country groups, except possibly for Group 5 (the rest of the world). However, even in the case of this group the number of output gap pairs that meet both the unit root and the co-trending tests is at most $6.6 \%$. This is obtained when the ADF-WS(p) test is applied at the $10 \%$ level with the augmentation order, $p$, selected by the AIC. See Table 5 .

Some of the negative results obtained so far on output convergence could be attributable to the known low power of the ADF type tests in small samples. As noted earlier, a possible alternative would be to use the $K P S S(\ell)$ test given by (23). In application of this test the choice of the lag window, $\ell$, is very important and need to be chosen carefully in relation to the sample size $T$. Here we follow the time series literature and use $\ell \approx 0.75 T^{1 / 3}$. Accordingly, we computed the KPSS statistic for all output pairs over the three sample periods and by different country groups. The test results are summarized in Table 6 and report the proportions of output gap pairs for which the null of stationarity is rejected. These results are marginally more favourable to the convergence hypothesis. For the "world" as a whole and over the period 1961-2000, the stationarity hypothesis is not rejected in the case of $20 \%$ (14\%) of the output gap pairs if the KPSS test is carried out at the 5\% (10\%) significance level. Similar results are also obtained for other periods. However, the test results disaggregated by country groups are more mixed; with the Middle East and North Africa having the highest proportion of stationary output gap pairs and Asia, Australia and New Zealand (group 3) having the lowest proportions. For example, over the period 1961-2000 and using the 5\% significance level, only $11 \%$ of the output gap pairs turned out to be stationary for Asia, Australia and New Zealand group, whilst for the countries in the Middle East and North Africa this proportion turned out to be around $53 \%$. These differences, however, need to be viewed with caution, since the number of countries in the country groupings differ markedly. For example, over the 1961-2000 period there are 9 countries in the Middle East and North African region as compared to 15 countries in Asia, Australia and New Zealand group, and 23 countries in the

\footnotetext{
${ }^{13}$ For a comparative small sample power analysis of the unit root tests see Smith, Leybourne, Kim, and Newbold (2004) and references cited therein.

${ }^{14}$ The membership of the different country groups is given in Table 1.
} 
North and Latin American region.

Overall, the KPSS test results are more favourable to the output convergence hypothesis as compared to the results based on ADF type tests. Although, at the world level the evidence for output convergence is still rather week. The results by country groups are somewhat stronger and provide some support for the hypothesis of "club convergence".

\subsubsection{Overall Measures of Output Convergence}

Similar conclusions can be reached if overall dispersion measures, such as the mean difference (MD) coefficients defined by (25) or its population weighted counterpart, (26), are used. ${ }^{15}$ The estimates of $\Delta_{t}$ and $\Delta_{t}^{*}$ computed over the period 1961-2000 for the "world" and the five different country groups are displayed in Figure 10. As note earlier, under the null of output convergence none of these measures should have unit roots or exhibit a deterministic trends. The results of the various unit root tests applied to $\Delta_{t}$ and $\Delta_{t}^{*}$ are summarized in Tables 7 and 8. Using $\Delta_{t}$, the unit root hypothesis is rejected in the case of groups 4 and 5 , whilst if we use $\Delta_{t}^{*}$ the unit root hypothesis is not rejected for any of the country groups if the ADF-WS test is applied and is rejected in the case of groups 1 and 4 if the standard ADF test is applied. But, as can be seen from Figure 1, the time plots of $\Delta_{t}$ and $\Delta_{t}^{*}$ show clear trends with the possible exception of the measures for the Middle East and North Africa. Although, the trends in the equal weighted and the population weighted dispersion measures can be markedly different. This is most noticeable in the case of the dispersion measures computed for the "world" where the un-weighted measure, $\Delta_{t}$, is trended upward, whilst the population weighted measure, $\Delta_{t}^{*}$, starts to trend downwards from early 1980's, largely reflecting the significant economic growth of the populous countries in South East Asia and particularly China.

\subsection{Evidence on Output Convergence Using Maddison Se- ries}

Given the relatively short sample sizes of most output series in the PWT data set, it would be of interest to see if our main conclusions are much affected by using the longer series that are compiled by Maddison. Maddison's longer series should help with power of the tests, but are limited in the number of countries that they cover, and are likely to be subject to important measurement errors. As before, initially we started our investigation by testing for the presence of unit roots in the log per capita output gaps across all country pairs disaggregated into three country groups: advanced countries $(N=17)$, the countries in South Europe $(N=5)$, and the Latin American economies $(N=8)$. The results of these tests are summarized in Table 9 . We shall focus on the group of advanced economies, since the numbers of output gap pairs in the other two groups are

\footnotetext{
${ }^{15}$ Other dispersion measures, such as the standard deviation of log per capita output, also lead to very similiar conclusions and to save space will not be discussed here.
} 
rather small. For the advanced economies the ADF-WS test yields the highest rejection rates, possibly reflecting its higher small sample power as discussed above. The order of augmentation is much more critical for the test outcomes, since Maddison's series cover a much wider range of events and are likely to show a higher degree of serial correlations. The tests based on the orders of augmentation selected by AIC (namely $\mathrm{p}_{A I C}$ ) are likely to be most reliable as it is unlikely that the ADF regressions for all the seventeen series in the group could have the same order. At the $5 \%$ significance level, the unit root hypothesis in the output gap pairs is rejected for 36 out of the 136 possible output gap pairs, or $26.5 \%$ of the sample. This figure rises to $39 \%$ (53 out of 136) if we conduct the tests at the $10 \%$ level. These are substantially above the $5 \%$ and $10 \%$ nominal levels. However, as before we also need to test for co-trending and check to see how many of the 36 (or 53) output gap pairs have a constant mean. Table 10 summarizes the results of testing these I(0) output gap pairs for the presence of linear deterministic trends. According to these results the number of output gap pairs that survive both tests are 13 and 19, depending on whether the first stage unit root test has been carried out at $5 \%$ or $10 \%$ levels. Note that the significance level of the second stage test (that tests for the presence of a linear trend) is set at $5 \%$. Therefore, only $10-14 \%$ of the 136 output gap pairs can be regarded as convergent.

Although the power aspect of the above testing procedure might have been enhanced by the much longer series being used, the two-stage nature of the test is likely to bias the test in favour of non-stationary outcomes. Once again the KPSS test could be relevant here. Table 11 provides the KPSS test results applied to the Maddison series. The results are very similar to the ones obtained using the ADF-based two stage procedure. According to the KPSS test around $7-12 \%$ of the 136 output pair gaps in the group of advanced economies pass the convergence test. This could suggest some degree of convergence, but the percentage of the output gap pairs that pass the test is still very low and could have arisen by chance.

\section{Evidence on Growth Convergence}

Having find little evidence in support of output convergence, it might be of interest to consider the weaker hypothesis of growth convergence. Within the framework of the stochastic Slow growth model, the country-specific growth rates are given by (9) which yield the following "growth gap" equations:

$$
g_{i t}-g_{j t}=g_{i}-g_{j}+\xi_{i j t},
$$

where $\xi_{i j t}$ is given by

$\xi_{i j t}=\left(\Delta u_{i t}-\Delta u_{j t}\right)-\alpha\left\{\left(\frac{1}{1-\beta_{i} L}\right)\left(\Delta^{2} u_{i t}+\Delta^{2} v_{i t}\right)-\left(\frac{1}{1-\beta_{j} L}\right)\left(\Delta^{2} u_{j t}+\Delta^{2} v_{j t}\right)\right\}$.

Under the stochastic Slow growth model for all $i$ and $j, \xi_{i j t}$ will follow a mean zero stationary process even if there are unit roots in the processes generating 
technology or employment. Therefore, the growth convergence hypothesis

$$
H_{g c}: g_{i}=g_{j}, \text { for all } i \text { and } j,
$$

can be tested using the following $A R\left(p_{i j}\right)$ approximations of (28):

$$
g_{i t}-g_{j t}=g_{i j}+\sum_{s=1}^{p_{i j}} \varphi_{i j}\left(g_{i, t-s}-g_{j, t-s}\right)+\nu_{i j t},
$$

where $g_{i j}=g_{i}-g_{j}$, and $p_{i j}$ is selected empirically using selection criteria such as AIC. The growth convergence hypothesis forms a subset of the output convergence hypothesis defined by (15) and (16).

Tests of the growth convergence hypothesis can now be carried out by testing the insignificance of the short-run or the long-run intercept terms in the growth gap regressions defined by (29). These intercept terms, respectively, are given by $g_{i j}$ and

$$
g_{i j}^{*}=\frac{g_{i j}}{1-\sum_{s=1}^{p_{i j}} \varphi_{i j}} .
$$

The results of these tests applied to PWT and Maddison series for the various sub-periods and country groupings are summarized in Tables 12 and 13. These tables give the proportions of statistically insignificant (at the $5 \%$ level) shortrun and long-run intercept terms. Once again recall that these proportions are estimated consistently for sufficiently large $T$ and $N$, even though the errors $\nu_{i j t}$ are cross sectionally correlated.

Overall, the results are quite favourable to the growth convergence hypothesis, with the Maddison series being particularly supportive of the hypothesis. It is also interesting that the results are quite robust to the sample periods or whether the short-run or the long-run intercept terms are used in the test. For the PWT series the growth convergence hypothesis is not rejected for around $72 \%$ of the country pairs, irrespective of the sample period considered. For the Maddison growth series this figure is above $95 \%$, quite a conclusive outcome. The PWT series also show some interesting geographical variations, with the growth convergence hypothesis being more wide spread across the countries in group 4 and 5 (Middle East North Africa and the Rest of the World), and less so in the case of countries in group 3 (Asia, Australia and New Zealand).

\section{Concluding Remarks}

In this paper we have highlighted the importance of using log per capita output gaps in the analysis of output or growth convergence. We have also illustrated how such pair-wise measures of divergence between any two given economies, when suitably averaged, can be linked to measures of output inequality such as the mean difference coefficient, which is the numerator of the Gini coefficient routinely used in studies of income inequality within across countries. Seen from this perspective, the pair-wise output gaps form the basic building blocks 
of the stochastic processes of income distribution dynamics which has been the subject of extensive research in the literature on club convergence. However, it is important to make a distinction between log per capita output gaps and per capita output gaps, with the former being relevant for the analysis of output convergence in the context of stochastic Slow type growth models, whilst the latter being more appropriate for cross country studies of income inequality. ${ }^{16}$

The focus of our empirical analysis has been on the unit root and trending properties of log per capita output gaps across different countries in a global context, as well as in specific geographical regions. Using both PWT and Maddison data sets we have found little evidence of log per capita output convergence at a global level, although there seems to be some evidence of club convergence, so long as the concept of a "club" is loosely defined to mean countries with pair-wise output gaps that are stationary with a constant mean. This concept does not, of course, rule out the possibility of the club membership to change over time, which renders it more of historical interest rather than immediate relevance for policy analysis. Further analysis of the nature of the clubs and the characteristics of their membership would be needed for a better understanding of the growth process for policy analysis. Such an endeavour is beyond the scope of the present paper.

Finally, the approach of this paper can be readily applied to the analysis of income inequality, by considering the unit root and trending properties of per capita output gaps. Such an analysis will be more closely linked to overall measure of income inequality such as the Gini coefficient, and suggest that in using the Gini coefficient the choice of the denominator need to be approach more carefully under the possibility of unit roots in per capita outputs.

\footnotetext{
${ }^{16}$ Trends in global income inequality have been recently investigated by Bourguignon and Morrison (2002) and Sala-i-Martin (2002a ,2002b).
} 


\section{A Appendix: ADF-GLS and ADF-WS Unit Root Tests}

The ADF-GLS test is proposed by Elliott, Rothenberg and Stock (1996) and is argued that in general has better power characteristics than the standard ADF test. Although, Pantula et al. (1994) and Leybourne (1995) provide Monte Carlo evidence suggesting that the MAX-ADF test proposed by Leybourne and the ADF-WS test of Park and Fuller (1995) could be more powerful than the ADF-GLS test.

\section{A.1 ADF-GLS Unit Root Test}

Consider the ordered series $x_{t}, t=1,2, \ldots, T$ and make the following transformations:

$$
\begin{aligned}
x_{\rho 1} & =x_{1}, \\
x_{\rho t} & =x_{t}-\rho x_{t-1}, \text { for } t=2, \ldots, T,
\end{aligned}
$$

where $\rho$ is a fixed coefficient to be set by the tester (see below). Similarly

$$
\begin{aligned}
& z_{11}(\rho)=1 \\
& z_{1 t}(\rho)=(1-\rho), \text { for } t=2, \ldots, T,
\end{aligned}
$$

and

$$
\begin{aligned}
& z_{21}(\rho)=1 \\
& z_{2 t}(\rho)=t-\rho(t-1), \text { for } t=2, \ldots, T .
\end{aligned}
$$

\section{A.1.1 Models with intercepts but without trend}

Compute the OLS regression of $x_{\rho t}$ on $z_{1 t}(\rho)$

$$
\hat{\beta}_{\rho}=\frac{x_{1}+(1-\rho) \sum_{t=2}^{T}\left(x_{t}-\rho x_{t-1}\right)}{1+(1-\rho)^{2}(T-1)},
$$

and then deviations

$$
w_{t}=x_{t}-\hat{\beta}_{\rho}, \text { for } t=1,2, \ldots, T
$$

and carry out $\operatorname{ADF}(\mathrm{p})$ test applied to $w_{t}$. It is recommended that $\rho$ is set to $1-7 / T$.

\section{A.1.2 Models with an intercept and a linear trend}

Compute the OLS regression coefficients of $x_{\rho t}$ on $z_{1 t}(\rho)$, and $z_{2 t}(\rho)$, and denote these coefficients by $\hat{\beta}_{1 \rho}$ and $\hat{\beta}_{2 \rho}$ and then compute

$$
w_{t}=x_{t}-\hat{\beta}_{1 \rho}-\hat{\beta}_{2 \rho} t, \text { for } t=1,2, \ldots, T
$$


and then apply the $\operatorname{ADF}(\mathrm{p})$ procedure to $w_{t}$, with

$$
\begin{aligned}
& \rho=1-\frac{c_{\mu}}{T}, \text { for models with intercept only } \\
& \rho=1-\frac{c_{\tau}}{T}, \text { for models with intercept and linear trend }
\end{aligned}
$$

We follow Elliott et al.'s recommendation and use the following parameter values in the application of the ADF-GLS test to the output gaps:

$$
c_{\mu}=7, c_{\tau}=13.5
$$

\section{A.2 The ADF-WS Unit Root Test}

The Weighted Symmetric ADF (WS-ADF) has been proposed by Park and Fuller (1995) and analyzed further (using Monte Carlo simulations) by Pantula et al. (1994). A detailed discussion is also provided by Fuller (1996, Section 10.1.3). The WS-ADF attempts to increase the power of the unit root test by making use of the fact that any stationary autoregressive process can be given a forward as well as a backward representation. An estimator of the autoregressive parameters that take account of this property is generally known as WS estimators. Consider the $p^{t h}$ order (backward) ADF regression

$$
x_{t}=\rho x_{t-1}+\sum_{j=1}^{p} \delta_{j} \Delta x_{t-j}+\varepsilon_{t}^{b},
$$

then under stationarity we also have

$$
x_{t}=\rho x_{t+1}-\sum_{j=1}^{p} \delta_{j} \Delta x_{t+j+1}+\varepsilon_{t}^{f} .
$$

The WS estimator of $\rho$ is obtained by solving the following weighted least squares problem

$$
\begin{aligned}
Q(\rho, \boldsymbol{\delta})= & \sum_{t=p+2}^{T} w_{t}\left[x_{t}-\rho x_{t-1}-\sum_{j=1}^{p} \delta_{j} \Delta x_{t-j}\right]^{2}+ \\
& \sum_{t=p+2}^{T}\left(1-w_{t-p}\right)\left[x_{t-p-1}-\rho x_{t-p}+\sum_{j=1}^{p} \delta_{j} \Delta x_{t-p+j}\right]^{2},
\end{aligned}
$$

or equivalently

$$
\begin{aligned}
Q(\rho, \boldsymbol{\delta})= & \sum_{t=p+2}^{T} w_{t}\left[x_{t}-\rho x_{t-1}-\sum_{j=1}^{p} \delta_{j} \Delta x_{t-j}\right]^{2}+ \\
& \sum_{t=1}^{T-p-1}\left(1-w_{t+1}\right)\left[x_{t}-\rho x_{t+1}+\sum_{j=1}^{p} \delta_{j} \Delta x_{t+j+1}\right]^{2},
\end{aligned}
$$


where

$$
w_{t}=\left\{\begin{array}{c}
0, \text { for } 1 \leq t \leq p+1, \\
\frac{t-p-1}{T-2 p}, \text { for } p+1<t \leq T-p, \\
1, \text { for } T-p<t \leq T,
\end{array}\right.
$$

and assuming that $T \geq 2(p+1)$.

Let $\hat{\rho}$ and $\hat{\boldsymbol{\delta}}=\left(\hat{\boldsymbol{\delta}}_{1}, \ldots, \hat{\delta}_{p}\right)^{\prime}$ be the estimators of $\rho$ and $\boldsymbol{\delta}$ that minimize $Q(\rho, \boldsymbol{\delta})$. Then the WS-ADF $(\mathrm{p})$ statistic is given by

$$
\frac{\hat{\rho}-1}{\sqrt{\widehat{\operatorname{Var}}(\hat{\rho})}},
$$

where

$$
\begin{gathered}
\widehat{\operatorname{Var}}(\hat{\rho})=\hat{\sigma}^{2} a_{\rho \rho} \\
\hat{\sigma}^{2}=\frac{Q(\hat{\rho}, \hat{\boldsymbol{\delta}})}{T-p-2} \text { for a model with intercept, } \\
\hat{\sigma}^{2}=\frac{Q(\hat{\rho}, \hat{\boldsymbol{\delta}})}{T-p-3} \text { for a model with a linear trend, }
\end{gathered}
$$

and $a_{\rho \rho}$ is the element $(1,1)$ in the inverse of $\partial^{2} Q(\rho, \boldsymbol{\delta}) / \partial \theta \partial \theta^{\prime}$, where $\boldsymbol{\theta}=(\hat{\rho}, \hat{\boldsymbol{\delta}})^{\prime}$.

\section{A.2.1 An Explicit Solution}

Let $\mathbf{z}_{b t}=\left(x_{t-1}, \Delta x_{t-1}, \ldots, \Delta x_{t-p}\right)^{\prime}$ and $\mathbf{z}_{f t}=\left(x_{t+1},-\Delta x_{t+2},-\Delta x_{t+3}, \ldots,-\Delta x_{t+p+1}\right)^{\prime}$, then it is easily seen that

$$
\hat{\boldsymbol{\theta}}=\mathbf{A}_{T}^{-1} \mathbf{b}_{T},
$$

where

$$
\begin{aligned}
\mathbf{A}_{T} & =\sum_{t=p+2}^{T} w_{t} \mathbf{z}_{b t} \mathbf{z}_{b t}^{\prime}+\sum_{t=1}^{T-p-1}\left(1-w_{t+1}\right) \mathbf{z}_{f t} \mathbf{z}_{f t}^{\prime}, \\
\mathbf{b}_{T} & =\sum_{t=p+2}^{T} w_{t} \mathbf{z}_{b t} x_{t}+\sum_{t=1}^{T-p-1}\left(1-w_{t+1}\right) \mathbf{z}_{f t} x_{t} .
\end{aligned}
$$

Also

$$
\frac{\partial^{2} Q(\rho, \boldsymbol{\delta})}{\partial \theta \partial \theta^{\prime}}=\mathbf{A}_{T}
$$

and

$$
\operatorname{Var}(\hat{\boldsymbol{\theta}})=\hat{\sigma}^{2} \mathbf{A}_{T}^{-1}
$$

The output gap series are de-trended before computing the ADF-WS statistics. The critical values of the ADF, ADF-GLS and ADF-WS tests for the sample sizes and the augmentation orders relevant to the present application are provided in Table A. 


\section{References}

Barro, R.J., and Sala-i-Martin, X. (1995): Economic Growth, New York: McGraw-Hill.

Bernard, A. B. and Durlauf, S. (1995): Convergence in International Output, Journal of Applied Econometrics, 10, 97-108.

Bernard, A. B. and Durlauf, S. (1996): Interpreting tests of the Convergence Hypothesis, Journal of Econometrics, 71, 161-73.

Bianchi, M. (1997): Testing for Convergence: Evidence from Nonparametric Multimodality Tests, Journal of Applied Econometrics, 12 (4), July-A ugust, 393-409.

Binder, M. and Pesaran, M.H. (1999): Stochastic Growth Models and Their Econometric Implications, Journal of Economic Growth, 4, 139-183.

Bourguignon, F. and Morrison, C. (2002): Inequality Among World Citizens: 1820-1992, American Economic Review, 92 (4), 727-744.

Camarero, M., Flôres, R. G. and Tamarit, C. (2002): Multivariate Time Series Evidence of International Output Convergence in Mercosur, www.cepremap.ens.fr/sce2002/papers/paper87.pdf.

Canova, F. (2001): Testing for Convergence Clubs in Income Per Capita: A Predictive Density Approach, HWWA Discussion Paper, No. 139, Hamburg Institute of International Economics.

Durlauf, S.N., and Johnson P.A. (1995): Multiple Regimes and Cross-Country Growth Behaviour, Journal of Applied Econometrics, 10, 365-384.

Durlauf, S.N. and Quah, D.T. (1999): The New Empirics of Economic Growth, in: J.P. Taylor and M. Woodford (eds.): Handbook of Macroeconomics, Amsterdam: North Holland.

Elliot, G., Rothenberg, T.J. and Stock, J.H. (1996): Efficient Tests for an Autoregressive Unit Root, Econometrica, 64, 813-836.

Fuller, W.A. (1996): Introduction to Statistical Time Series, Second Edition, Wiley.

Galor, O. (1996): Convergence? Inference from Theoretical Models, The Economic Journal, $106,1056-1069$.

Heston, A., Summers, R. and Aten, B. (2002): Penn World Table Version 6.1, Center for International Comparisons at the University of Pennsylvania (CICUP), October 2002.

Hobijn B., and Franses, P.H. (2000): Asymptotically Perfect and Relative Convergence of Productivity, Journal of Applied Econometrics, 15, 59-81.

Islam, N. (1995): Growth Empirics: A Panel Data Approach, Quarterly Journal of Economics, 110, 1127-1170.

Islam, N. (2003): What have we learnt from the Convergence Debate? Journal of Economic Surveys, 17, 309-362.

Kwiatkowski, D., Phillips, P.C.B., Schmidt, P. and .Shin, Y. (1992): Testing the Null Hypothesis of Stationarity Against the Alternative of a Unit Root, Journal of Econometrics, $54,159-178$. 
Lee, K., Pesaran, M.H. and Smith, R. (1997): Growth and Convergence in a MultiCountry Empirical Stochastic Solow Model, Journal of Applied Econometrics, 12, 357-392.

Lee, K., Pesaran, M.H. and Smith, R. (1998): Growth Empirics: A Panel Data Approach - A Comment, Quarterly Journal of Economics, 113, 319-323.

Leybourne, S.J.(1995): Testing for Unit Roots using Forward and Reverse Dickey-Fuller Regressions, Oxford Bulletin of Economics and Statistics, 57, 559-571.

Luginbuhl, R. and Koopman, S.J. (2003): Convergence in European GDP Series: A Multivariate Common Converging Trend-Cycle Decomposition, Journal of Applied Econometrics, Forthcoming.

Maddison, A. (2003): The World Economy: Historical Statistics, OECD Development Centre, Paris.

Mankiw, N., Romer, D. and Weil, D. (1992): A Contribution to the Empirics of Economic Growth, Quarterly Journal of Economics, 107, 407-37.

Oxley, L. and Greasley, D. (1995): A Time-Series Perspective on Convergence: Australia, UK and USA since 1870, The Economic Record, 71, 259-270.

Pantula, S.G., Gonzalez-Farias, G and Fuller, W.A. (1994): A Comparison of UnitRoot Test Criteria, Journal of Business and Economic Statistics, 12, 449-459.

Park, H.J. and Fuller, W.A. (1995): Alternative Estimators and Unit Root Tests for the Autoregressive Process, Journal of Time Series Analysis, 16, 415-429.

Pesaran, M. H., Shin, Y. and Smith, R.J. (2000): Structural Analysis Of Vector Error Correction Models with Exogenous I (1) Variables, Journal of Econometrics, Vol 97, pp.293343.

Quah, D. (1996a): Convergence Empirics Across Countries with (some) Capital Mobility, Journal of Economic Growth, vol.1, 95-124.

Quah, D. (1996b): Twin Peaks: Growth and Convergence in Models of Distribution Dynamics, The Economic Journal, vol.106, 1045-1055.

Quah, D. (1997): Empirics for Growth and Distribution: Polarization, Stratification and Convergence Club, Journal of Economic Growth, 2, 27-59.

Sala-i-Martin, X. (2002a): The Disturbing 'Rise' of the Global Income Inequality, NBER Working Paper 8904.

Sala-i-Martin, X. (2002b): The World Distribution of Income (Estimated from individual country distributions), NBER Working Paper 8933.

Smith, L. V., Leybourne, S., Kim, T-H. and Newbold P. (2004): More powerful panel data unit root tests with an application to mean reversion in real exchange rates, Journal of Applied Econometrics, 19, 147-170.

Temple, J. (1999): The New Growth Evidence, Journal of Economic Literature, 37, 112-156. 
Table 1a: Composition of Country Groups by Geographical Regions for the Different Sample Periods in the Penn World Tables (PWT)

\begin{tabular}{l|l}
\hline \multicolumn{1}{c|}{ Country group } & \multicolumn{1}{c}{ A: Sample period: 1951-2000 } \\
\hline $\begin{array}{l}\text { Group1 } \\
\begin{array}{l}\text { Europe (EU15 + Switzerland + } \\
\text { Norway) (16) }\end{array}\end{array}$ & $\begin{array}{l}\text { Austria, Belgium, Switzerland, Denmark, Spain, Finland, France, } \\
\text { Greece, Ireland, Italy, Luxembourg, Netherlands, Norway, Portugal, } \\
\text { Sweden, United Kingdom }\end{array}$ \\
$\begin{array}{l}\text { Group2 } \\
\text { North and Latin America (21) }\end{array}$ & $\begin{array}{l}\text { Argentina, Bolivia, Brazil, Canada, Chile, Colombia, Costa Rica, } \\
\text { Dominican Republic, Ecuador, Guatemala, Honduras, Mexico, } \\
\text { Nicaragua, Panama, Peru, Paraguay, El Salvador, Trinidad \& Tobago, } \\
\text { Uruguay, USA, Venezuela }\end{array}$ \\
$\begin{array}{l}\text { Group 3 } \\
\text { Asia + Australia + New Zealand (8) }\end{array}$ & $\begin{array}{l}\text { Australia, India, Japan, Sri Lanka, New Zealand, Pakistan, Philippines, } \\
\text { Thailand }\end{array}$ \\
$\begin{array}{l}\text { Group 4 } \\
\text { Middle East and North Africa (4) } \\
\begin{array}{l}\text { Group 5 } \\
\text { Rest of the World (7) }\end{array}\end{array}$ & $\begin{array}{l}\text { Israel, Egypt, Morocco, Turkey } \\
\text { Ethiopia, Iceland, Kenya, Mauritius, Nigeria, Uganda, South Africa }\end{array}$ \\
\hline
\end{tabular}

B: Sample period: 1961-2000

\section{Group2}

\begin{tabular}{l} 
Country group \\
\hline Group1 \\
Europe (EU15 + Switzerland + \\
Norway) (16)
\end{tabular}

North and Latin America (23)
Group 3

Asia + Australia + New Zealand (15)

\section{Group 4}

Middle East and North Africa (9)

Group 5

Rest of the World (36)

\section{Composition}

Austria, Belgium, Switzerland, Denmark, Spain, Finland, France, Greece, Ireland, Italy, Luxembourg, Netherlands, Norway, Portugal, Sweden, United Kingdom

Argentina, Barbados, Bolivia, Brazil, Canada, Chile, Colombia, Costa Rica, Dominican Republic, Ecuador, Guatemala, Honduras, Jamaica, Mexico, Nicaragua, Panama, Peru, Paraguay, El Salvador, Trinidad \& Tobago, Uruguay, USA, Venezuela

Australia, Bangladesh, China, Hong Kong, Indonesia, India, Japan, Korea, Malaysia, Nepal, New Zealand, Pakistan, Philippines, Sri Lanka, Thailand

Algeria, Egypt, Iran, Israel, Jordan, Morocco, Syria, Tunisia, Turkey

Burundi, Benin, Burkina Faso, Cote d'Ivoire, Cameroon, Congo, Comoros, Cape Verde, Ethiopia, Gabon, Ghana, Guinea, Gambia, Guinea-Bissau, Equatorial Guinea, Iceland, Kenya, Lesotho, Madagascar, Mali, Mozambique, Mauritius, Malawi, Niger, Nigeria,

Romania, Rwanda, Senegal, Seychelles, Chad, Togo, Tanzania, Uganda, South Africa, Zambia, Zimbabwe

C: Sample period: 1971-2000

The same as those listed under the sample period 1961-2000 with Germany and Hungary added to Group 1 and Group 5, respectively. The numbers in brackets are the total number of countries in each grou 
Table 1b: Composition of Country Groups for Maddison's Data Set ${ }^{1}$

\begin{tabular}{l|l}
\hline \multicolumn{1}{c|}{ Country group } & \multicolumn{1}{c}{ Composition } \\
\hline $\begin{array}{l}\text { Advanced countries (17) } \\
\mathbf{1 8 7 0 - 2 0 0}\end{array}$ & $\begin{array}{l}\text { Australia, Austria, Belgium, Canada, Denmark, Finland, France, } \\
\text { Germany, Italy, Japan, Netherlands, New Zealand, Norway, Sweden, } \\
\text { Switzerland, United Kingdom, USA }\end{array}$ \\
$\begin{array}{l}\text { South Europe (5) } \\
\mathbf{1 9 2 3 - 2 0 0 0}\end{array}$ & Greece, Ireland, Portugal, Spain, Turkey \\
$\begin{array}{l}\text { Latin America (8) } \\
\mathbf{1 9 0 0 - 2 0 0 0}\end{array}$ & Argentina, Brazil, Chile, Colombia, Mexico, Peru, Venezuela, Uruguay \\
\hline
\end{tabular}

Note: ${ }^{1}$ The numbers in brackets are the total number of countries in each group. The sample periods are 1870-2000, 1923-2000, and 1900-2000 for Advanced countries, South Europe, and Latin America, respectively. 


\section{Table 2: Proportions of Output Gap Pairs for which the Unit Root Hypothesis are Rejected - PWT Series}

\begin{tabular}{|c|c|c|c|c|c|c|}
\hline \multirow{2}{*}{\begin{tabular}{|c|} 
Sample Period \\
Number of \\
Countries \\
\\
$\begin{array}{c}\text { Number of Country } \\
\text { Pairs }\end{array}$
\end{tabular}} & \multicolumn{2}{|c|}{$N=56$} & \multicolumn{2}{|c|}{$\mathrm{N}=99$} & \multicolumn{2}{|c|}{$\mathrm{N}=101$} \\
\hline & \multicolumn{2}{|c|}{1540} & \multicolumn{2}{|c|}{4851} & \multicolumn{2}{|c|}{5050} \\
\hline $\begin{array}{c}\text { Tests/Significance } \\
\text { Level }\end{array}$ & $10 \%$ & $5 \%$ & $10 \%$ & $5 \%$ & $10 \%$ & $5 \%$ \\
\hline \multicolumn{7}{|l|}{ ADF (p) } \\
\hline $\mathrm{p}=1$ & 9.94 & 5.84 & 11.05 & 5.50 & 12.22 & 6.30 \\
\hline $\mathrm{p}=2$ & 6.30 & 2.60 & 7.11 & 3.28 & 8.89 & 4.48 \\
\hline$p=3$ & 7.34 & 3.31 & 9.09 & 4.74 & 11.70 & 6.36 \\
\hline$p=4$ & 5.06 & 1.75 & 8.80 & 4.54 & 9.98 & 5.70 \\
\hline $\mathrm{p}(\mathrm{AIC})$ & 10.06 & 6.04 & 12.10 & 6.20 & 13.84 & 7.68 \\
\hline \multicolumn{7}{|l|}{ ADF-GLS (p) } \\
\hline $\mathrm{p}=1$ & 11.04 & 6.43 & 8.72 & 5.13 & 8.46 & 3.98 \\
\hline $\mathrm{p}=2$ & 7.21 & 4.22 & 5.24 & 2.70 & 4.77 & 1.98 \\
\hline$p=3$ & 7.47 & 3.44 & 6.78 & 3.50 & 7.13 & 3.49 \\
\hline$p=4$ & 3.77 & 1.75 & 6.99 & 3.24 & 4.93 & 2.44 \\
\hline $\mathrm{p}(\mathrm{AIC})$ & 11.04 & 6.56 & 9.67 & 5.81 & 9.76 & 4.95 \\
\hline \multicolumn{7}{|l|}{ ADF-WS (p) } \\
\hline $\mathrm{p}=1$ & 14.03 & 7.73 & 11.75 & 6.80 & 13.29 & 7.33 \\
\hline$p=2$ & 9.16 & 5.45 & 8.74 & 4.25 & 8.95 & 4.06 \\
\hline$p=3$ & 11.88 & 5.91 & 10.31 & 5.98 & 14.10 & 7.33 \\
\hline$p=4$ & 7.60 & 2.73 & 11.89 & 6.78 & 11.31 & 5.45 \\
\hline $\mathrm{p}(\mathrm{AIC})$ & 13.96 & 7.92 & 13.01 & 7.63 & 14.83 & 8.53 \\
\hline & & & & & & \\
\hline
\end{tabular}

1. The unit root tests are based on augmented Dickey-Fuller (ADF) regressions with an intercept and a linear trend, and are carried out at the 10\% and $5 \%$ significance levels. ADF $(p)$ denotes the standard ADF test of order $p$. ADF-GLS is due to Elliot et al. (1996) that corrects for trends, and ADF-WS is the weighted symmetric version of the ADF test proposed by Park and Fuller (1995). See Appendix A for computational details and the critical values. 
Table 3: Numbers of I(0) Output Gap Pairs with Insignificant Linear Trend Coefficients - PWT Series

\begin{tabular}{|c|c|c|c|c|c|c|}
\hline \multirow{3}{*}{$\begin{array}{c}\text { Sample Period } \\
\begin{array}{c}\text { Number of } \\
\text { Countries }\end{array} \\
\begin{array}{c}\text { Number of Country } \\
\text { Pairs }\end{array}\end{array}$} & \multicolumn{2}{|c|}{$1951-2000(\mathrm{~T}=50)$} & \multicolumn{2}{|c|}{$1961-2000(\mathrm{~T}=40)$} & \multicolumn{2}{|c|}{$1971-2000(\mathrm{~T}=30)$} \\
\hline & \multicolumn{2}{|c|}{$\mathrm{N}=56$} & \multicolumn{2}{|c|}{$\mathrm{N}=99$} & \multicolumn{2}{|c|}{$\mathrm{N}=101$} \\
\hline & \multicolumn{2}{|c|}{1540} & \multicolumn{2}{|c|}{4851} & \multicolumn{2}{|c|}{5050} \\
\hline $\begin{array}{c}\text { Tests/Significant } \\
\text { Level }\end{array}$ & $10 \%$ & $5 \%$ & $10 \%$ & $5 \%$ & $10 \%$ & $5 \%$ \\
\hline \multicolumn{7}{|l|}{ ADF (p) } \\
\hline $\mathrm{p}=1$ & $26(153)$ & $13(90)$ & $105(536)$ & $42(267)$ & $127(617)$ & $70(318)$ \\
\hline$p=2$ & $14(97)$ & $5(40)$ & $52(345)$ & $26(159)$ & $77(449)$ & $31(226)$ \\
\hline $\mathrm{p}=3$ & $16(113)$ & $7(51)$ & $71(441)$ & $43(230)$ & $91(591)$ & $43(321)$ \\
\hline $\mathrm{p}=4$ & $12(78)$ & $3(27)$ & $83(427)$ & $45(220)$ & $79(504)$ & $46(288)$ \\
\hline $\mathrm{p}(\mathrm{AIC})$ & $24(155)$ & $12(93)$ & $117(587)$ & $49(301)$ & $144(699)$ & $80(388)$ \\
\hline \multicolumn{7}{|l|}{ ADF-GLS (p) } \\
\hline $\mathrm{p}=1$ & $40(170)$ & $17(99)$ & $103(423)$ & $37(249)$ & $102(427)$ & $50(201)$ \\
\hline$p=2$ & $23(111)$ & $10(65)$ & $46(254)$ & $21(131)$ & $55(241)$ & $23(100)$ \\
\hline$p=3$ & $22(115)$ & $6(53)$ & $67(329)$ & $30(170)$ & $73(360)$ & $29(176)$ \\
\hline $\mathrm{p}=4$ & $12(58)$ & $5(27)$ & $76(339)$ & $35(157)$ & $60(249)$ & $30(123)$ \\
\hline $\mathrm{p}(\mathrm{AIC})$ & $38(170)$ & $16(101)$ & $116(469)$ & $47(282)$ & $117(493)$ & $62(250)$ \\
\hline \multicolumn{7}{|l|}{ ADF-WS (p) } \\
\hline $\mathrm{p}=1$ & $49(216)$ & $24(119)$ & $139(570)$ & $68(330)$ & $170(671)$ & $89(370)$ \\
\hline $\mathrm{p}=2$ & $28(141)$ & $14(84)$ & $85(424)$ & $36(206)$ & $102(452)$ & $37(205)$ \\
\hline $\mathrm{p}=3$ & $32(183)$ & $15(91)$ & $105(500)$ & $48(290)$ & $169(712)$ & $59(370)$ \\
\hline $\mathrm{p}=4$ & $23(117)$ & $6(42)$ & $140(577)$ & $65(329)$ & $151(571)$ & $55(275)$ \\
\hline $\mathrm{p}(\mathrm{AIC})$ & $48(215)$ & $23(122)$ & $154(631)$ & $80(370)$ & $191(749)$ & $100(431)$ \\
\hline
\end{tabular}

1. The numbers in brackets are the total number of country pairs for which the unit root hypothesis were rejected at the specified significance levels. These are the rejection frequencies in Table 2 multiplied by the number of country pairs. Tests of the significance of linear trends are conducted at the $5 \%$ significance level. 
Table 4: Proportion of Output Gap Pairs for which the Unit Root Hypothesis is Rejected by Country Groups - PWT Series

\begin{tabular}{|c|c|c|c|c|c|c|}
\hline \multirow{2}{*}{\begin{tabular}{|l|} 
Sample period \\
Tests/Significant level \\
\end{tabular}} & \multicolumn{2}{|c|}{$1951-2000(T=50)$} & \multicolumn{2}{|c|}{$1961-2000(T=40)$} & \multicolumn{2}{|c|}{$1971-2000(T=30)$} \\
\hline & $10 \%$ & $5 \%$ & $10 \%$ & $5 \%$ & $10 \%$ & $5 \%$ \\
\hline & \multicolumn{6}{|c|}{ Group 1} \\
\hline Number of countries & \multirow{2}{*}{\multicolumn{2}{|c|}{$\begin{array}{c}16 \\
120\end{array}$}} & \multirow{2}{*}{\multicolumn{2}{|c|}{$\begin{array}{c}16 \\
120\end{array}$}} & \multicolumn{2}{|c|}{$\begin{array}{c}17 \\
136\end{array}$} \\
\hline Number of country pairs & & & & & & \\
\hline \multicolumn{7}{|l|}{$A D F(p)$} \\
\hline$p=1$ & 6.67 & 4.17 & 7.50 & 1.67 & 13.24 & 4.41 \\
\hline$p=2$ & 5.00 & 1.67 & 4.17 & 1.67 & 7.35 & 2.21 \\
\hline$p=3$ & 5.00 & 3.33 & 5.00 & 3.33 & 11.03 & 5.88 \\
\hline$p=4$ & 5.83 & 0.83 & 4.17 & 1.67 & 8.82 & 2.94 \\
\hline $\mathrm{p}(\mathrm{AIC})$ & 6.67 & 4.17 & 7.50 & 1.67 & 14.71 & 5.15 \\
\hline \multicolumn{7}{|l|}{ ADF-GLS(p) } \\
\hline$p=1$ & 6.67 & 3.33 & 5.00 & 1.67 & 10.29 & 5.88 \\
\hline$p=2$ & 5.00 & 0.00 & 0.83 & 0.00 & 6.62 & 2.94 \\
\hline$p=3$ & 5.00 & 1.67 & 5.00 & 2.50 & 16.18 & 8.09 \\
\hline$p=4$ & 3.33 & 0.83 & 4.17 & 0.00 & 5.15 & 2.94 \\
\hline $\mathrm{p}(\mathrm{AIC})$ & 5.83 & 3.33 & 5.00 & 1.67 & 18.38 & 11.03 \\
\hline \multicolumn{7}{|l|}{ ADF-WS(p) } \\
\hline$p=1$ & 8.33 & 4.17 & 6.67 & 3.33 & 15.44 & 9.56 \\
\hline$p=2$ & 6.67 & 1.67 & 5.83 & 0.00 & 8.82 & 4.41 \\
\hline$p=3$ & 8.33 & 1.67 & 7.50 & 4.17 & 13.97 & 5.88 \\
\hline$p=4$ & 4.17 & 1.67 & 8.33 & 5.00 & 7.35 & 1.47 \\
\hline \multirow[t]{2}{*}{$p(A I C)$} & 9.17 & 4.17 & 6.67 & 3.33 & 18.38 & 11.76 \\
\hline & \multicolumn{6}{|c|}{ Group 2} \\
\hline Number of countries & \multirow{2}{*}{\multicolumn{2}{|c|}{$\begin{array}{c}21 \\
210\end{array}$}} & \multirow{2}{*}{\multicolumn{2}{|c|}{$\begin{array}{c}23 \\
253\end{array}$}} & \multirow{2}{*}{\multicolumn{2}{|c|}{$\begin{array}{c}23 \\
253\end{array}$}} \\
\hline Number of country pairs & & & & & & \\
\hline \multicolumn{7}{|l|}{\begin{tabular}{|l|}
$A D F(p)$ \\
\end{tabular}} \\
\hline$p=1$ & 6.19 & 3.33 & 7.91 & 3.16 & 7.51 & 5.14 \\
\hline$p=2$ & 5.24 & 1.43 & 5.53 & 1.19 & 3.95 & 1.58 \\
\hline$p=3$ & 7.14 & 2.38 & 5.14 & 1.58 & 7.51 & 2.37 \\
\hline$p=4$ & 6.67 & 4.17 & 2.37 & 0.40 & 3.16 & 0.79 \\
\hline $\mathrm{p}(\mathrm{AIC})$ & 7.14 & 3.81 & 7.91 & 3.56 & 8.30 & 5.53 \\
\hline \multicolumn{7}{|l|}{ ADF-GLS(p) } \\
\hline$p=1$ & 6.19 & 3.33 & 6.32 & 1.98 & 9.88 & 2.77 \\
\hline$p=2$ & 4.76 & 2.86 & 4.35 & 1.19 & 3.56 & 0.79 \\
\hline$p=3$ & 6.19 & 2.86 & 5.53 & 1.98 & 5.93 & 3.16 \\
\hline$p=4$ & 4.76 & 3.33 & 3.56 & 0.79 & 2.77 & 1.19 \\
\hline $\mathrm{p}(\mathrm{AIC})$ & 7.14 & 4.29 & 7.51 & 2.37 & 10.67 & 3.16 \\
\hline \multicolumn{7}{|l|}{ ADF-WS(p) } \\
\hline$p=1$ & 7.62 & 3.81 & 9.49 & 5.53 & 12.65 & 7.51 \\
\hline$p=2$ & 5.71 & 2.38 & 7.11 & 3.16 & 10.67 & 2.77 \\
\hline$p=3$ & 9.52 & 3.33 & 10.67 & 5.53 & 13.04 & 7.11 \\
\hline$p=4$ & 7.62 & 3.81 & 9.09 & 2.77 & 7.91 & 3.95 \\
\hline $\mathrm{p}(\mathrm{AIC})$ & 8.57 & 4.76 & 10.67 & 6.32 & 14.23 & 8.30 \\
\hline
\end{tabular}


Table 4 (continued): Proportion of Output Gap Pairs for which the Unit Root Hypothesis is Rejected by Country Groups - PWT Series

\begin{tabular}{|c|c|c|c|c|c|c|}
\hline \multirow{2}{*}{\begin{tabular}{|l|} 
Sample period \\
Tests/Significant level
\end{tabular}} & \multicolumn{2}{|c|}{$1951-2000(\mathrm{~T}=50)$} & \multicolumn{2}{|c|}{$1961-2000(T=40)$} & \multicolumn{2}{|c|}{$1971-2000(T=30)$} \\
\hline & $10 \%$ & $5 \%$ & $10 \%$ & $5 \%$ & $10 \%$ & $5 \%$ \\
\hline & \multicolumn{6}{|c|}{ Group 3} \\
\hline Number of countries & \multirow{2}{*}{\multicolumn{2}{|c|}{$\begin{array}{c}8 \\
28\end{array}$}} & \multirow{2}{*}{\multicolumn{2}{|c|}{$\begin{array}{c}15 \\
105\end{array}$}} & \multirow{2}{*}{\multicolumn{2}{|c|}{$\begin{array}{c}15 \\
105\end{array}$}} \\
\hline Number of country pairs & & & & & & \\
\hline \multicolumn{7}{|l|}{$A D F(p)$} \\
\hline$p=1$ & 3.57 & 3.57 & 6.67 & 3.81 & 6.67 & 3.81 \\
\hline$p=2$ & 7.14 & 0.00 & 6.67 & 4.76 & 12.38 & 3.81 \\
\hline$p=3$ & 7.14 & 3.57 & 8.57 & 4.76 & 17.14 & 10.48 \\
\hline$p=4$ & 3.57 & 0.00 & 6.67 & 1.90 & 14.29 & 6.67 \\
\hline $\mathrm{p}(\mathrm{AIC})$ & 7.14 & 7.14 & 7.62 & 4.76 & 9.52 & 7.62 \\
\hline \multicolumn{7}{|l|}{ ADF-GLS(p) } \\
\hline$p=1$ & 3.57 & 3.57 & 2.86 & 0.95 & 1.90 & 0.95 \\
\hline$p=2$ & 7.14 & 3.57 & 4.76 & 1.90 & 1.90 & 0.95 \\
\hline$p=3$ & 10.71 & 7.14 & 5.71 & 1.90 & 5.71 & 4.76 \\
\hline$p=4$ & 7.14 & 0.00 & 2.86 & 0.95 & 0.95 & 0.95 \\
\hline $\mathrm{p}(\mathrm{AIC})$ & 3.57 & 3.57 & 4.76 & 1.90 & 2.86 & 1.90 \\
\hline \multicolumn{7}{|l|}{ ADF-WS(p) } \\
\hline$p=1$ & 0.00 & 0.00 & 2.86 & 1.90 & 9.52 & 2.86 \\
\hline$p=2$ & 3.57 & 3.57 & 6.67 & 1.90 & 6.67 & 2.86 \\
\hline$p=3$ & 17.86 & 14.29 & 11.43 & 6.67 & 9.52 & 5.71 \\
\hline$p=4$ & 7.14 & 0.00 & 9.52 & 6.67 & 10.48 & 1.90 \\
\hline \multirow[t]{2}{*}{$\mathrm{p}(\mathrm{AIC})$} & 3.57 & 3.57 & 4.76 & 2.86 & 10.48 & 2.86 \\
\hline & \multicolumn{6}{|c|}{ Group 4} \\
\hline Number of countries & \multirow{2}{*}{\multicolumn{2}{|c|}{$\begin{array}{l}4 \\
6\end{array}$}} & \multirow{2}{*}{\multicolumn{2}{|c|}{$\begin{array}{c}9 \\
36\end{array}$}} & \multirow{2}{*}{\multicolumn{2}{|c|}{$\begin{array}{c}9 \\
36\end{array}$}} \\
\hline Number of country pairs & & & & & & \\
\hline \multicolumn{7}{|l|}{ ADF(p) } \\
\hline$p=1$ & 0.00 & 0.00 & 2.78 & 0.00 & 11.11 & 5.56 \\
\hline$p=2$ & 16.67 & 0.00 & 0.00 & 0.00 & 11.11 & 8.33 \\
\hline$p=3$ & 16.67 & 16.67 & 8.33 & 0.00 & 22.22 & 8.33 \\
\hline$p=4$ & 16.67 & 0.00 & 5.56 & 0.00 & 13.89 & 8.33 \\
\hline $\mathrm{p}(\mathrm{AIC})$ & 0.00 & 0.00 & 2.78 & 0.00 & 13.89 & 8.33 \\
\hline \multicolumn{7}{|l|}{ ADF-GLS(p) } \\
\hline$p=1$ & 16.67 & 0.00 & 5.56 & 2.78 & 11.11 & 8.33 \\
\hline$p=2$ & 16.67 & 16.67 & 5.56 & 0.00 & 11.11 & 2.78 \\
\hline$p=3$ & 16.67 & 16.67 & 16.67 & 2.78 & 11.11 & 8.33 \\
\hline$p=4$ & 16.67 & 16.67 & 11.11 & 5.56 & 11.11 & 5.56 \\
\hline$P(A I C)$ & 16.67 & 0.00 & 8.33 & 2.78 & 13.89 & 8.33 \\
\hline \multicolumn{7}{|l|}{ ADF-WS(p) } \\
\hline$p=1$ & 33.33 & 0.00 & 2.78 & 2.78 & 2.78 & 2.78 \\
\hline$p=2$ & 16.67 & 16.67 & 2.78 & 0.00 & 2.78 & 2.78 \\
\hline$p=3$ & 33.33 & 16.67 & 16.67 & 8.33 & 11.11 & 5.56 \\
\hline$p=4$ & 16.67 & 16.67 & 16.67 & 5.56 & 11.11 & 5.56 \\
\hline$P(A I C)$ & 33.33 & 0.00 & 5.56 & 2.78 & 5.56 & 2.78 \\
\hline
\end{tabular}


Table 4 (continued): Proportions of Output Gap Pairs for which the Unit Root Hypothesis are Rejected by Country Groups - PWT Series

\begin{tabular}{|c|c|c|c|c|c|c|}
\hline \multirow{2}{*}{\begin{tabular}{|l|} 
Sample period \\
Tests/Significant level \\
\end{tabular}} & \multicolumn{2}{|c|}{$1951-2000(\mathrm{~T}=50)$} & \multicolumn{2}{|c|}{$1961-2000(\mathrm{~T}=40)$} & \multicolumn{2}{|c|}{$1971-2000(\mathrm{~T}=30)$} \\
\hline & $10 \%$ & $5 \%$ & $10 \%$ & $5 \%$ & $10 \%$ & $5 \%$ \\
\hline & \multicolumn{6}{|c|}{ Group 5} \\
\hline \begin{tabular}{|l|} 
Number of countries \\
Number of country pairs
\end{tabular} & \multicolumn{2}{|c|}{$\begin{array}{c}7 \\
21\end{array}$} & \multicolumn{2}{|c|}{$\begin{array}{c}36 \\
630 \\
\end{array}$} & \multicolumn{2}{|c|}{$\begin{array}{c}37 \\
666\end{array}$} \\
\hline$A D F(p)$ & & & & & & \\
\hline$p=1$ & 28.57 & 23.81 & 17.94 & 10.48 & 16.22 & 8.71 \\
\hline$p=2$ & 14.29 & 9.52 & 11.11 & 6.03 & 8.86 & 3.15 \\
\hline$p=3$ & 14.29 & 4.76 & 14.13 & 8.10 & 10.21 & 5.41 \\
\hline$p=4$ & 0.00 & 0.00 & 13.81 & 6.67 & 9.31 & 5.56 \\
\hline $\mathrm{P}(\mathrm{AIC})$ & 28.57 & 23.81 & 19.05 & 11.27 & 16.97 & 9.61 \\
\hline \multicolumn{7}{|l|}{ ADF-GLS(p) } \\
\hline$p=1$ & 28.57 & 28.57 & 13.81 & 9.52 & 11.71 & 5.86 \\
\hline$p=2$ & 14.29 & 9.52 & 8.73 & 3.65 & 4.80 & 1.35 \\
\hline$p=3$ & 14.29 & 4.76 & 8.25 & 4.76 & 6.16 & 2.25 \\
\hline$p=4$ & 9.52 & 0.00 & 7.62 & 4.29 & 5.86 & 3.00 \\
\hline $\mathrm{P}(\mathrm{AIC})$ & 28.57 & 28.57 & 14.76 & 10.00 & 12.61 & 6.16 \\
\hline \multicolumn{7}{|l|}{ ADF-WS(p) } \\
\hline$p=1$ & 33.33 & 23.81 & 17.30 & 11.90 & 18.77 & 11.41 \\
\hline$p=2$ & 19.05 & 19.05 & 14.44 & 7.78 & 10.06 & 5.26 \\
\hline$p=3$ & 23.81 & 9.52 & 13.17 & 8.41 & 15.47 & 7.81 \\
\hline$p=4$ & 9.52 & 0.00 & 13.17 & 8.10 & 12.31 & 7.81 \\
\hline$P(A I C)$ & 33.33 & 23.81 & 18.25 & 12.70 & 19.67 & 12.61 \\
\hline
\end{tabular}

1. See the notes to Table 2. For the definitions of country groups see Table 1a. 
Table 5: Numbers of Stationary Output Gap Pairs with Insignificant Linear Trend Coefficients by Country Groups - PWT Series

\begin{tabular}{|c|c|c|c|c|c|c|}
\hline \multirow{2}{*}{\begin{tabular}{|l|} 
Sample period \\
Tests/Significant level
\end{tabular}} & \multicolumn{2}{|c|}{$1951-2000(T=50)$} & \multicolumn{2}{|c|}{$1961-2000(T=40)$} & \multicolumn{2}{|c|}{$1971-2000(T=30)$} \\
\hline & $10 \%$ & $5 \%$ & $10 \%$ & $5 \%$ & $10 \%$ & $5 \%$ \\
\hline & \multicolumn{6}{|c|}{ Group 1} \\
\hline Number of countries & \multicolumn{2}{|c|}{16} & \multirow{2}{*}{\multicolumn{2}{|c|}{$\begin{array}{c}16 \\
120\end{array}$}} & \multirow{2}{*}{\multicolumn{2}{|c|}{$\begin{array}{c}17 \\
136\end{array}$}} \\
\hline Number of country pairs & \multicolumn{2}{|c|}{120} & & & & \\
\hline ADF(p) & & & & & & \\
\hline$p=1$ & $1(8)$ & $0(5)$ & $1(9)$ & $0(2)$ & $5(18)$ & $1(6)$ \\
\hline$p=2$ & $1(6)$ & $0(2)$ & $0(5)$ & $0(2)$ & $3(10)$ & 1(3) \\
\hline$p=3$ & $1(6)$ & $1(4)$ & $0(6)$ & $0(4)$ & $2(15)$ & 1(8) \\
\hline$p=4$ & $2(7)$ & $0(1)$ & $0(5)$ & $0(2)$ & $1(12)$ & $0(4)$ \\
\hline$P(A I C)$ & $1(8)$ & $0(5)$ & $1(9)$ & $0(2)$ & $5(20)$ & $1(7)$ \\
\hline \multicolumn{7}{|l|}{ ADF-GLS(p) } \\
\hline$p=1$ & $3(8)$ & $1(4)$ & $1(6)$ & $0(2)$ & $3(14)$ & $2(8)$ \\
\hline$p=2$ & $3(6)$ & $0(0)$ & $1(1)$ & $0(0)$ & 2(9) & $2(4)$ \\
\hline$p=3$ & $1(6)$ & $0(2)$ & $2(6)$ & $0(3)$ & $7(22)$ & $1(11)$ \\
\hline$p=4$ & $1(4)$ & $1(1)$ & $2(5)$ & $0(0)$ & $0(7)$ & $0(4)$ \\
\hline$P(A I C)$ & $2(7)$ & $1(4)$ & $1(6)$ & $0(2)$ & $11(25)$ & $4(15)$ \\
\hline \multicolumn{7}{|l|}{ ADF-WS(p) } \\
\hline$p=1$ & $3(10)$ & $2(5)$ & $2(8)$ & $1(4)$ & $8(21)$ & $4(13)$ \\
\hline$p=2$ & $4(8)$ & $1(2)$ & $3(7)$ & $0(0)$ & $4(12)$ & $1(6)$ \\
\hline$p=3$ & $4(10)$ & $0(2)$ & $2(9)$ & $1(5)$ & $4(19)$ & $0(8)$ \\
\hline$p=4$ & $2(5)$ & $1(2)$ & $3(10)$ & $1(6)$ & $1(10)$ & $0(2)$ \\
\hline \multirow[t]{2}{*}{$\mathrm{P}(\mathrm{AIC})$} & $4(11)$ & $2(5)$ & $2(8)$ & $1(4)$ & $10(25)$ & $5(16)$ \\
\hline & \multicolumn{6}{|c|}{ Group 2} \\
\hline Number of countries & \multirow{2}{*}{\multicolumn{2}{|c|}{$\begin{array}{c}21 \\
210\end{array}$}} & \multirow{2}{*}{\multicolumn{2}{|c|}{$\begin{array}{c}23 \\
253\end{array}$}} & \multirow{2}{*}{\multicolumn{2}{|c|}{23}} \\
\hline Number of country pairs & & & & & & \\
\hline ADF(p) & & & & & & \\
\hline$p=1$ & $3(13)$ & $1(7)$ & $3(20)$ & $1(8)$ & $3(19)$ & $2(13)$ \\
\hline$p=2$ & $2(11)$ & $1(3)$ & $3(14)$ & $2(3)$ & $0(10)$ & $0(4)$ \\
\hline$p=3$ & $3(15)$ & 1(5) & $0(13)$ & $0(4)$ & $1(19)$ & $0(6)$ \\
\hline$p=4$ & $2(14)$ & $0(5)$ & $1(6)$ & $1(1)$ & $0(8)$ & $0(2)$ \\
\hline$P(A I C)$ & $3(15)$ & $1(8)$ & $3(20)$ & $1(9)$ & $3(21)$ & $2(14)$ \\
\hline \multicolumn{7}{|l|}{ ADF-GLS(p) } \\
\hline$p=1$ & $3(13)$ & $1(7)$ & $6(16)$ & $1(5)$ & $6(25)$ & $1(7)$ \\
\hline$p=2$ & $2(10)$ & $0(6)$ & $5(11)$ & $0(3)$ & $0(9)$ & $0(2)$ \\
\hline$p=3$ & $3(13)$ & $0(6)$ & $3(14)$ & $0(5)$ & $0(15)$ & $0(8)$ \\
\hline$p=4$ & $1(10)$ & $0(7)$ & $3(9)$ & $1(2)$ & $1(7)$ & $1(3)$ \\
\hline$P(A I C)$ & $3(15)$ & $1(9)$ & $7(19)$ & $1(6)$ & $6(27)$ & $1(8)$ \\
\hline \multicolumn{7}{|l|}{ ADF-WS(p) } \\
\hline$p=1$ & $3(16)$ & $1(8)$ & $8(24)$ & $3(14)$ & $6(32)$ & $5(19)$ \\
\hline$p=2$ & $3(12)$ & $1(5)$ & $7(18)$ & $3(8)$ & $3(27)$ & $0(7)$ \\
\hline$p=3$ & $3(20)$ & $1(7)$ & $8(27)$ & 2(14) & $4(33)$ & $1(18)$ \\
\hline$p=4$ & $3(16)$ & $0(8)$ & $5(23)$ & $2(7)$ & $5(20)$ & $1(10)$ \\
\hline$P(A I C)$ & $3(18)$ & $1(10)$ & $9(27)$ & $4(16)$ & $6(36)$ & $5(21)$ \\
\hline
\end{tabular}


Table 5 (continued): Numbers of Stationary Output Gap Pairs with Insignificant Linear Trend Coefficients by Country Groups - PWT Series

\begin{tabular}{|c|c|c|c|c|c|c|}
\hline \multirow{2}{*}{\begin{tabular}{|l|} 
Sample period \\
Tests/Significant level
\end{tabular}} & \multicolumn{2}{|c|}{$1951-2000(T=50)$} & \multicolumn{2}{|c|}{$1961-2000(T=40)$} & \multicolumn{2}{|c|}{$1971-2000(T=30)$} \\
\hline & $10 \%$ & $5 \%$ & $10 \%$ & $5 \%$ & $10 \%$ & $5 \%$ \\
\hline & \multicolumn{6}{|c|}{ Group 3} \\
\hline Number of countries & \multirow{2}{*}{\multicolumn{2}{|c|}{$\begin{array}{c}8 \\
28\end{array}$}} & \multirow{2}{*}{\multicolumn{2}{|c|}{$\begin{array}{c}15 \\
105\end{array}$}} & \multirow{2}{*}{\multicolumn{2}{|c|}{$\begin{array}{c}15 \\
105\end{array}$}} \\
\hline Number of country pairs & & & & & & \\
\hline \multicolumn{7}{|l|}{ ADF $(p)$} \\
\hline$p=1$ & $0(1)$ & $0(1)$ & $0(7)$ & $0(4)$ & $0(7)$ & $0(4)$ \\
\hline$p=2$ & $0(2)$ & $0(0)$ & $0(7)$ & $0(5)$ & $0(13)$ & $0(4)$ \\
\hline$p=3$ & $0(2)$ & $0(1)$ & $0(9)$ & $0(5)$ & $1(18)$ & 1(11) \\
\hline$p=4$ & $0(1)$ & $0(0)$ & $0(7)$ & $0(2)$ & $1(15)$ & $1(7)$ \\
\hline$P(A I C)$ & $0(2)$ & $0(2)$ & $0(8)$ & $0(5)$ & $1(10)$ & $1(8)$ \\
\hline \multicolumn{7}{|l|}{ ADF-GLS(p) } \\
\hline$p=1$ & $0(1)$ & $0(1)$ & $0(3)$ & $0(1)$ & $1(2)$ & $0(1)$ \\
\hline$p=2$ & $1(2)$ & $0(1)$ & $0(5)$ & $0(2)$ & $0(2)$ & $0(1)$ \\
\hline$p=3$ & $0(3)$ & $0(2)$ & $0(6)$ & $0(2)$ & $0(6)$ & $0(5)$ \\
\hline$p=4$ & $0(2)$ & $0(0)$ & $0(3)$ & $0(1)$ & $0(1)$ & $0(1)$ \\
\hline$P(A I C)$ & $0(1)$ & $0(1)$ & $0(5)$ & $0(2)$ & $1(3)$ & $0(2)$ \\
\hline \multicolumn{7}{|l|}{ ADF-WS(p) } \\
\hline$p=1$ & $0(0)$ & $0(0)$ & $0(3)$ & $0(2)$ & $1(10)$ & $1(3)$ \\
\hline$p=2$ & $0(1)$ & $0(1)$ & $0(7)$ & $0(2)$ & $1(7)$ & $0(3)$ \\
\hline$p=3$ & $1(5)$ & $0(4)$ & $0(12)$ & $0(7)$ & $0(10)$ & $0(6)$ \\
\hline$p=4$ & $0(2)$ & $0(0)$ & $0(10)$ & $0(7)$ & $0(11)$ & $0(2)$ \\
\hline \multirow[t]{2}{*}{$\mathrm{P}(\mathrm{AIC})$} & $0(1)$ & $0(1)$ & $0(5)$ & $0(3)$ & $1(11)$ & $1(3)$ \\
\hline & \multicolumn{6}{|c|}{ Group 4} \\
\hline Number of countries & \multirow{2}{*}{\multicolumn{2}{|c|}{$\begin{array}{l}4 \\
6\end{array}$}} & \multirow{2}{*}{\multicolumn{2}{|c|}{$\begin{array}{c}9 \\
36\end{array}$}} & \multirow{2}{*}{\multicolumn{2}{|c|}{9}} \\
\hline Number of country pairs & & & & & & \\
\hline \multicolumn{7}{|l|}{$A D F(p)$} \\
\hline$p=1$ & $0(0)$ & $0(0)$ & 1(1) & $0(0)$ & $1(4)$ & $1(2)$ \\
\hline$p=2$ & $0(1)$ & $0(0)$ & $0(0)$ & $0(0)$ & $1(4)$ & $1(3)$ \\
\hline$p=3$ & $0(1)$ & $0(1)$ & 1(3) & $0(0)$ & $2(8)$ & $1(3)$ \\
\hline$p=4$ & $0(1)$ & $0(0)$ & $1(2)$ & $0(0)$ & $1(5)$ & $0(3)$ \\
\hline$P(A I C)$ & $0(0)$ & $0(0)$ & 1(1) & $0(0)$ & $1(5)$ & 1(3) \\
\hline \multicolumn{7}{|l|}{ ADF-GLS(p) } \\
\hline$p=1$ & $1(1)$ & $0(0)$ & $2(2)$ & $1(1)$ & $3(4)$ & $2(3)$ \\
\hline$p=2$ & $0(1)$ & $0(1)$ & 2(2) & $0(0)$ & $4(4)$ & $1(1)$ \\
\hline$p=3$ & $0(1)$ & $0(1)$ & $3(6)$ & $1(1)$ & $3(4)$ & $2(3)$ \\
\hline$p=4$ & $0(1)$ & $0(1)$ & $3(4)$ & $2(2)$ & $2(4)$ & $1(2)$ \\
\hline$P(A I C)$ & $1(1)$ & $0(0)$ & $3(3)$ & $1(1)$ & $3(5)$ & $2(3)$ \\
\hline \multicolumn{7}{|l|}{ ADF-WS(p) } \\
\hline$p=1$ & $2(2)$ & $0(0)$ & 1(1) & $1(1)$ & $1(1)$ & $1(1)$ \\
\hline$p=2$ & $0(1)$ & $0(1)$ & 1(1) & $0(0)$ & 1(1) & 1(1) \\
\hline$p=3$ & $1(2)$ & $0(1)$ & $3(6)$ & $1(3)$ & $3(4)$ & $1(2)$ \\
\hline$p=4$ & $0(1)$ & $0(1)$ & $5(6)$ & $1(2)$ & $1(4)$ & $1(2)$ \\
\hline $\mathrm{P}(\mathrm{AIC})$ & $2(2)$ & $0(0)$ & $2(2)$ & $1(1)$ & $1(2)$ & 1(1) \\
\hline
\end{tabular}


Table 5 (continued): Numbers of Stationary Output Gap Pairs with Insignificant Linear Trend Coefficients by Country Groups - PWT Series

\begin{tabular}{|c|c|c|c|c|c|c|}
\hline \multirow{2}{*}{\begin{tabular}{|l|} 
Sample period \\
Tests/Significant level
\end{tabular}} & \multicolumn{2}{|c|}{$1951-2000(T=50)$} & \multicolumn{2}{|c|}{$1961-2000(T=40)$} & \multicolumn{2}{|c|}{$1971-2000(T=30)$} \\
\hline & $10 \%$ & $5 \%$ & $10 \%$ & $5 \%$ & $10 \%$ & $5 \%$ \\
\hline & \multicolumn{6}{|c|}{ Group 5} \\
\hline Number of countries & \multirow{2}{*}{\multicolumn{2}{|c|}{$\begin{array}{c}7 \\
21\end{array}$}} & \multirow{2}{*}{\multicolumn{2}{|c|}{$\begin{array}{c}36 \\
630\end{array}$}} & \multirow{2}{*}{\multicolumn{2}{|c|}{$\begin{array}{c}37 \\
666\end{array}$}} \\
\hline Number of country pairs & & & & & & \\
\hline ADF(p) & & & & & & \\
\hline$p=1$ & $1(6)$ & $0(5)$ & $28(113)$ & $17(66)$ & $33(108)$ & $16(58)$ \\
\hline$p=2$ & $0(3)$ & $0(2)$ & $18(70)$ & $11(38)$ & 13(59) & $6(21)$ \\
\hline$p=3$ & $0(3)$ & $0(1)$ & $15(89)$ & $12(51)$ & $10(68)$ & $7(36)$ \\
\hline$P=4$ & $0(0)$ & $0(0)$ & 19(87) & $8(42)$ & $13(62)$ & $5(37)$ \\
\hline $\mathrm{P}(\mathrm{AIC})$ & $1(6)$ & $0(5)$ & $29(120)$ & $18(71)$ & $34(113)$ & $16(64)$ \\
\hline \multicolumn{7}{|l|}{ ADF-GLS(p) } \\
\hline$P=1$ & $1(6)$ & $1(6)$ & $24(87)$ & $9(60)$ & $22(78)$ & 11(39) \\
\hline$P=2$ & $0(3)$ & $0(2)$ & $11(55)$ & $5(23)$ & $8(32)$ & $4(9)$ \\
\hline$P=3$ & $0(3)$ & $0(1)$ & $7(52)$ & $5(30)$ & $8(41)$ & $3(15)$ \\
\hline$P=4$ & $0(2)$ & $0(0)$ & $9(48)$ & $5(27)$ & $7(39)$ & $4(20)$ \\
\hline$P(A I C)$ & $1(6)$ & $1(6)$ & $25(93)$ & $10(63)$ & $23(84)$ & $12(41)$ \\
\hline \multicolumn{7}{|l|}{ ADF-WS(p) } \\
\hline$P=1$ & $1(7)$ & $1(5)$ & $30(109)$ & $19(75)$ & $43(125)$ & $25(76)$ \\
\hline$P=2$ & $0(4)$ & $0(4)$ & $21(91)$ & 11(49) & $22(67)$ & $10(35)$ \\
\hline$P=3$ & $1(5)$ & $0(2)$ & $13(83)$ & $8(53)$ & $28(103)$ & $12(52)$ \\
\hline$P=4$ & $0(2)$ & $0(0)$ & $17(83)$ & $8(51)$ & 19(82) & $9(52)$ \\
\hline$P(A I C)$ & $1(7)$ & $1(5)$ & $30(115)$ & $19(80)$ & $44(131)$ & 26(84) \\
\hline
\end{tabular}

1. See the notes to Table 3. For the definitions of country groups see Table 1a. 
Table 6: Proportion of Output Gap Pairs for which the Stationarity Hypothesis is not Rejected using KPSS Test - PWT Series ${ }^{1}$

\begin{tabular}{|c|c|c|c|c|c|c|}
\hline \multicolumn{1}{|c|}{ (per cent) } \\
\hline Sample period & $\mathbf{1 9 5 1 - 2 0 0 0}(\mathbf{T}=\mathbf{5 0})$ & $\mathbf{1 9 6 1 - 2 0 0 0}(\mathbf{T = 4 0})$ & \multicolumn{2}{|c|}{$\mathbf{1 9 7 1 - 2 0 0 0}(\mathbf{T}=\mathbf{3 0})$} \\
\hline Significant level & $10 \%$ & $5 \%$ & $10 \%$ & $5 \%$ & $10 \%$ & $5 \%$ \\
\hline Group 1 & 19.17 & 30.00 & 16.67 & 27.50 & 16.91 & 22.79 \\
Group 2 & 14.76 & 24.29 & 18.18 & 24.11 & 18.58 & 27.27 \\
Group 3 & 14.29 & 21.43 & 6.67 & 11.43 & 7.62 & 12.38 \\
Group 4 & 50.00 & 50.00 & 33.33 & 52.78 & 27.78 & 52.78 \\
Group 5 & 4.76 & 19.05 & 18.25 & 24.29 & 19.07 & 28.38 \\
World & 16.17 & 23.05 & 14.33 & 20.74 & 16.22 & 23.11 \\
\hline
\end{tabular}

${ }^{1}$ The KPSS test statistics are computed as set out in Section 4.1 and are applied to deviations of output gap pairs from a constant mean. The relevant asymptotic critical values (obtained for the case with an intercept only) are 0.463 and 0.347 for $5 \%$ and $10 \%$ significant levels, respectively (see Kwiatkowski, Phillips, Schmidt and Shin (1992), Table 1). The window lags used is chosen approximately as $0.75(\sqrt[3]{T})$. Thus, for $\mathrm{T}=30$, 40 , and 50, the window lags used in the computation of the KPSS test statistic are 2, 3, and 4 , respectively. The total numbers of country pairs are given in Table 4 for country groups and in Table 2 for the world. 
Table 7: Unit Root Tests Applied to the Cross Section Mean Difference of Output for Different Country Groups - PWT Series, 1961-2000 (T=40)

\section{With intercept and linear trend}

\begin{tabular}{l|ccccc|c}
\hline \multicolumn{1}{c|}{ Tests/p } & $\mathbf{0}$ & $\mathbf{1}$ & $\mathbf{2}$ & $\mathbf{3}$ & $\mathbf{4}$ & $\mathbf{p ( A I C )}$ \\
\hline Group 1 & & & & & & \\
\hline ADF(p) & -2.499 & -2.329 & -2.376 & -2.313 & -2.232 & 0 \\
ADF-GLS $(p)$ & -0.477 & -0.855 & -1.090 & -1.192 & -1.250 & 0 \\
ADF-WS $(p)$ & -0.132 & -0.527 & -0.821 & -1.035 & -1.101 & 0 \\
Group 2 & & & & & & \\
\hline ADF(p) & -0.889 & -1.248 & -1.193 & -1.143 & -1.104 & 1 \\
ADF-GLS $(p)$ & -0.647 & -1.228 & -1.262 & -1.300 & -1.362 & 1 \\
ADF-WS(p) & -0.725 & -1.272 & -1.274 & -1.323 & -1.415 & 1 \\
Group 3 & & & & & & \\
\hline ADF(p) & -1.495 & -1.564 & -1.210 & -1.173 & -1.162 & 0 \\
ADF-GLS(p) & -0.308 & -0.780 & -0.700 & -0.794 & -0.988 & 0 \\
ADF-WS(p) & 0.045 & -0.492 & -0.452 & -0.600 & -0.858 & 0 \\
Group 4 & & & & & & \\
\hline ADF $(p)$ & -2.139 & -2.079 & -2.455 & -2.908 & $-3.834^{* *}$ & 4 \\
ADF-GLS(p) & -1.498 & -1.458 & -1.895 & -2.348 & $-3.087^{*}$ & 4 \\
ADF-WS $(p)$ & -1.707 & -1.479 & -2.012 & -2.641 & $-3.593^{* *}$ & 4 \\
Group 5 & & & & & & \\
\hline ADF $(p)$ & $-4.134^{* *}$ & -2.971 & -2.691 & -2.309 & -2.333 & 0 \\
ADF-GLS $(p)$ & $-3.492^{* *}$ & -2.373 & -2.085 & -1.716 & -1.751 & 0 \\
ADF-WS $(p)$ & $-3.956^{* *}$ & -2.729 & -2.368 & -2.053 & -2.107 & 0 \\
World & & & & & & \\
\hline ADF(p) & -1.944 & -1.649 & -1.544 & -1.402 & -1.772 & 0 \\
ADF-GLS $(p)$ & -1.995 & -1.702 & -1.603 & -1.466 & -1.853 & 0 \\
ADF-WS $(p)$ & -2.333 & -2.069 & -1.964 & -1.837 & -2.232 & 0 \\
\hline
\end{tabular}

1. ${ }^{*}$ and ${ }^{* *}$ indicate $10 \%$ and $5 \%$ significance levels, respectively. The critical values are given in Table $\mathrm{A}$. The concentration coefficient is computed as $\left(2 /(N(N-1)) \sum_{i} \sum_{j}\left|y_{i t}-y_{j t}\right|\right.$, where $\mathrm{i}, j=1,2, \ldots, \mathrm{N}$. 
Table 8: Unit Root Tests Applied to the Mean Difference with Population Weights for Different Country Groups: - PWT Series, 1961-2000 ( $T=40)$

With intercept and linear trend

\begin{tabular}{|c|c|c|c|c|c|c|}
\hline Tests/p & 0 & 1 & 2 & 3 & 4 & $p(A I C)$ \\
\hline \multicolumn{7}{|l|}{ Group 1} \\
\hline ADF $(p)$ & $-3.412^{*}$ & -3.111 & $-3.235^{\star}$ & $-3.486^{*}$ & $-3.990^{* *}$ & 4 \\
\hline ADF-GLS(p) & -0.671 & -1.141 & -1.265 & -1.743 & -2.520 & 4 \\
\hline ADF-WS(p) & 0.129 & -0.416 & -0.529 & -1.439 & -2.497 & 4 \\
\hline \multicolumn{7}{|l|}{ Group 2} \\
\hline$A D F(p)$ & -1.137 & -1.505 & -1.609 & -1.419 & -1.598 & 1 \\
\hline ADF-GLS(p) & -0.901 & -1.466 & -1.664 & -1.543 & -1.769 & 1 \\
\hline ADF-WS(p) & -0.897 & -1.466 & -1.655 & -1.563 & -1.836 & 1 \\
\hline \multicolumn{7}{|l|}{ Group 3} \\
\hline$A D F(p)$ & -2.518 & -2.866 & -2.853 & -2.574 & -2.520 & 1 \\
\hline ADF-GLS(p) & -2.506 & -2.895 & -2.883 & -2.587 & -2.533 & 1 \\
\hline ADF-WS(p) & -2.470 & -2.955 & -2.898 & -2.613 & -2.577 & 1 \\
\hline \multicolumn{7}{|l|}{ Group 4} \\
\hline$A D F(p)$ & -2.305 & -2.290 & -2.565 & $-3.216^{*}$ & $-3.390^{*}$ & 3 \\
\hline ADF-GLS(p) & -1.322 & -1.437 & -1.718 & -2.268 & -2.390 & 3 \\
\hline ADF-WS(p) & -1.377 & -1.361 & -1.625 & -2.553 & -2.774 & 3 \\
\hline \multicolumn{7}{|l|}{ Group 5} \\
\hline ADF(p) & -1.844 & -1.344 & -0.686 & -1.125 & -1.485 & 0 \\
\hline ADF-GLS(p) & -1.966 & -1.622 & -1.179 & -1.616 & -1.952 & 0 \\
\hline ADF-WS(p) & -2.201 & -1.829 & -1.377 & -1.834 & -2.197 & 0 \\
\hline \multicolumn{7}{|l|}{ World } \\
\hline$A D F(p)$ & -2.810 & -2.788 & -2.901 & -2.687 & -2.711 & 0 \\
\hline ADF-GLS(p) & -1.437 & -1.564 & -1.793 & -1.615 & -1.795 & 0 \\
\hline ADF-WS(p) & -1.224 & -1.375 & -1.568 & -1.360 & -1.668 & 0 \\
\hline
\end{tabular}

1. * and ${ }^{* *}$ indicate $10 \%$ and $5 \%$ significance levels, respectively. The critical values are given in Table A. The Mean Difference is computed as $\left(1-\sum_{i=1}^{N} \omega_{i t}^{2}\right)^{-1} \sum_{i=1}^{N} \sum_{j=1}^{N} \omega_{i t} \omega_{j t}\left|y_{i t}-y_{j t}\right|$, where $\omega_{i t}=P_{i t} / P_{t}$ with $P_{i t}$ being the population of country $i$ at time $t$, and $P_{i t}=\sum_{i=1}^{N} P_{i t}$. 
Table 9: Proportion of Output Gap Pairs for which the Unit Root Hypothesis is Rejected - Maddison Series ${ }^{1}$

\begin{tabular}{|c|c|c|c|c|c|c|}
\hline \multirow{3}{*}{\begin{tabular}{|l|} 
Group \\
Sample period \\
Tests/Significant Level
\end{tabular}} & \multicolumn{2}{|c|}{ Advanced Countries } & \multicolumn{2}{|c|}{ South Europe } & \multicolumn{2}{|c|}{ Latin America } \\
\hline & \multicolumn{2}{|c|}{$1870-2000(T=131)$} & \multicolumn{2}{|c|}{$1923-2000(T=78)$} & \multicolumn{2}{|c|}{$1900-2000(T=101)$} \\
\hline & $10 \%$ & $5 \%$ & $10 \%$ & $5 \%$ & $10 \%$ & $5 \%$ \\
\hline Number of countries & \multicolumn{2}{|c|}{17} & \multicolumn{2}{|c|}{5} & \multicolumn{2}{|c|}{8} \\
\hline Number of country pairs & \multicolumn{2}{|c|}{136} & \multicolumn{2}{|c|}{10} & \multicolumn{2}{|c|}{28} \\
\hline \multicolumn{7}{|l|}{ ADF(p) } \\
\hline$p=1$ & 41.18 & 30.15 & 30.00 & 30.00 & 3.57 & 3.57 \\
\hline$p=2$ & 32.35 & 22.06 & 30.00 & 30.00 & 0.00 & 0.00 \\
\hline$p=3$ & 33.09 & 24.26 & 30.00 & 30.00 & 0.00 & 0.00 \\
\hline$p=4$ & 26.47 & 13.97 & 30.00 & 30.00 & 0.00 & 0.00 \\
\hline $\mathrm{p}(\mathrm{AIC})$ & 28.68 & 16.91 & 30.00 & 30.00 & 0.00 & 0.00 \\
\hline \multicolumn{7}{|l|}{ ADF-GLS $(p)$} \\
\hline$p=1$ & 47.79 & 36.76 & 10.00 & 10.00 & 7.14 & 3.57 \\
\hline$p=2$ & 43.38 & 29.41 & 10.00 & 10.00 & 7.14 & 0.00 \\
\hline$p=3$ & 45.59 & 31.62 & 20.00 & 10.00 & 0.00 & 0.00 \\
\hline$p=4$ & 38.24 & 25.00 & 20.00 & 10.00 & 0.00 & 0.00 \\
\hline$p(A I C)$ & 35.29 & 23.53 & 20.00 & 10.00 & 0.00 & 0.00 \\
\hline \multicolumn{7}{|l|}{ ADF-WS(p) } \\
\hline$p=1$ & 49.26 & 38.97 & 10.00 & 10.00 & 14.29 & 3.57 \\
\hline$p=2$ & 44.85 & 30.88 & 20.00 & 10.00 & 10.71 & 0.00 \\
\hline$p=3$ & 47.06 & 34.56 & 20.00 & 10.00 & 3.57 & 0.00 \\
\hline$p=4$ & 41.18 & 27.21 & 20.00 & 10.00 & 3.57 & 0.00 \\
\hline $\mathrm{p}(\mathrm{AIC})$ & 38.97 & 26.47 & 20.00 & 10.00 & 3.57 & 0.00 \\
\hline
\end{tabular}

${ }^{1}$ The unit root tests are based on augmented Dickey-Fuller (ADF) regressions with an intercept and a linear trend, and are carried out at the $10 \%$ and $5 \%$ significance levels. ADF(p) denotes the standard ADF test of order p. ADF-GLS is due to Elliot et al. (1996) that corrects for trends, and ADF-WS is the weighted symmetric version of the ADF test proposed by Park and Fuller (1995). See Appendix A for computational details and the critical values. 
Table 10: Numbers of I(0) Output Gap Pairs with Insignificant Linear Trend Coefficients - Maddison Series ${ }^{1}$

\begin{tabular}{|c|c|c|c|c|c|c|}
\hline \multirow{3}{*}{\begin{tabular}{|l|} 
Group \\
Sample period \\
Tests/Significant Level \\
\end{tabular}} & \multicolumn{2}{|c|}{ Advanced } & \multicolumn{2}{|c|}{ South Europe } & \multicolumn{2}{|c|}{ Latin America } \\
\hline & \multicolumn{2}{|c|}{$1870-2000(T=131)$} & \multicolumn{2}{|c|}{$1923-2000(T=78)$} & \multicolumn{2}{|c|}{$1900-2000(T=101)$} \\
\hline & $10 \%$ & $5 \%$ & $10 \%$ & $5 \%$ & $10 \%$ & $5 \%$ \\
\hline Number of countries & \multicolumn{2}{|c|}{17} & \multicolumn{2}{|c|}{5} & \multicolumn{2}{|c|}{8} \\
\hline Number of country pairs & \multicolumn{2}{|c|}{136} & \multicolumn{2}{|c|}{10} & \multicolumn{2}{|c|}{28} \\
\hline \multicolumn{7}{|l|}{ ADF(p) } \\
\hline$p=1$ & $19(56)$ & $16(41)$ & $1(3)$ & $1(3)$ & $0(1)$ & $0(1)$ \\
\hline$p=2$ & $15(44)$ & $11(30)$ & $1(3)$ & $1(3)$ & $0(0)$ & $0(0)$ \\
\hline$p=3$ & $14(45)$ & $10(33)$ & $1(3)$ & $1(3)$ & $0(0)$ & $0(0)$ \\
\hline$p=4$ & $10(36)$ & $6(19)$ & $1(3)$ & $1(3)$ & $0(0)$ & $0(0)$ \\
\hline $\mathrm{p}(\mathrm{AIC})$ & $11(39)$ & $8(23)$ & $1(3)$ & $1(3)$ & $0(0)$ & $0(0)$ \\
\hline \multicolumn{7}{|l|}{ ADF-GLS(p) } \\
\hline$p=1$ & $29(65)$ & $21(50)$ & $1(1)$ & $1(1)$ & $1(2)$ & $0(1)$ \\
\hline$p=2$ & $25(59)$ & $18(40)$ & $1(1)$ & $1(1)$ & $1(2)$ & $0(0)$ \\
\hline$p=3$ & $26(62)$ & $18(43)$ & $2(2)$ & $1(1)$ & $0(0)$ & $0(0)$ \\
\hline$p=4$ & $20(52)$ & $14(34)$ & $2(2)$ & 1(1) & $0(0)$ & $0(0)$ \\
\hline $\mathrm{p}(\mathrm{AIC})$ & $18(48)$ & 13(32) & $2(2)$ & 1(1) & $0(0)$ & $0(0)$ \\
\hline \multicolumn{7}{|l|}{ ADF-WS(p) } \\
\hline$p=1$ & $29(67)$ & $20(53)$ & $1(1)$ & $1(1)$ & $1(4)$ & $0(1)$ \\
\hline$p=2$ & $25(61)$ & $18(42)$ & $2(2)$ & $1(1)$ & $1(3)$ & $0(0)$ \\
\hline$p=3$ & $25(64)$ & $18(47)$ & $2(2)$ & 1(1) & $0(1)$ & $0(0)$ \\
\hline$p=4$ & $21(56)$ & $13(37)$ & $2(2)$ & $1(1)$ & $0(1)$ & $0(0)$ \\
\hline$p(A I C)$ & $19(53)$ & $13(36)$ & $2(2)$ & 1(1) & $0(1)$ & $0(0)$ \\
\hline
\end{tabular}

${ }^{1}$ The numbers in brackets are the total number of country pairs for which the unit root hypothesis were rejected at the specified significance levels. These are the rejection frequencies in Table 2 multiplied by the number of country pairs. Tests of the significance of linear trends are conducted at the $5 \%$ significance level. 
Table 11: Proportion of Output Gap Pairs for which the Stationarity Hypothesis is not Rejected using KPSS Test - Maddison Series ${ }^{1}$

(per cent)

\begin{tabular}{|c|c|c|c|c|c|c|}
\hline Country group & \multicolumn{2}{|c|}{ Advanced } & \multicolumn{2}{|c|}{ South Europe } & \multicolumn{2}{|c|}{ Latin America } \\
\hline Sample period & \multicolumn{2}{|c|}{$1870-2000(T=131)$} & \multicolumn{2}{|c|}{$1923-2000(\mathrm{~T}=78)$} & \multicolumn{2}{|c|}{$1900-2000(T=101)$} \\
\hline Window lag & \multicolumn{2}{|c|}{4} & \multicolumn{2}{|c|}{3} & \multicolumn{2}{|c|}{3} \\
\hline Number of countries & \multicolumn{2}{|c|}{17} & \multicolumn{2}{|c|}{5} & \multicolumn{2}{|c|}{8} \\
\hline Number of country pairs & \multicolumn{2}{|c|}{136} & \multicolumn{2}{|c|}{10} & \multicolumn{2}{|c|}{28} \\
\hline Significant level & $10 \%$ & $5 \%$ & $10 \%$ & $5 \%$ & $10 \%$ & $5 \%$ \\
\hline KPSS & 7.35 & 11.76 & 30.00 & 20.00 & 3.57 & 7.14 \\
\hline
\end{tabular}

${ }^{1}$ The KPSS test statistics are computed as set out in Section 4.1 and are applied to deviations of output gap pairs from a constant mean. The relevant asymptotic critical values (obtained for the case with an intercept only) are 0.463 and 0.347 for $5 \%$ and $10 \%$ significant levels, respectively (see Kwiatkowski, Phillips, Schmidt and Shin (1992), Table 1). The window lags used are computed approximately as $0.75(\sqrt[3]{T})$. Thus, for $T=78,101$, and 131 , the window lags used in the computation of the KPSS test statistic are 3,3 , and 4 , respectively. 
Table 12: Proportion of Insignificant Short run and Long Run Intercept Terms in the Output Growth Gap Regressions - PWT Series

\begin{tabular}{|c|c|c|c|c|c|c|}
\hline & \multicolumn{2}{|c|}{$\mathrm{T}=30$} & \multicolumn{2}{|c|}{$\mathrm{T}=40$} & \multicolumn{2}{|c|}{$\mathrm{T}=50$} \\
\hline & SR & LR & SR & LR & SR & LR \\
\hline & \multicolumn{6}{|c|}{ World } \\
\hline Total Number of country pairs & \multicolumn{2}{|c|}{5050} & \multicolumn{2}{|c|}{4851} & \multicolumn{2}{|c|}{1540} \\
\hline$p=0$ & 70.50 & 70.50 & 69.82 & 69.82 & 66.30 & 66.30 \\
\hline$p=1$ & 80.34 & 76.44 & 78.46 & 74.91 & 80.32 & 76.43 \\
\hline$p=2$ & 81.35 & 73.66 & 78.66 & 73.00 & 79.16 & 73.83 \\
\hline$p=3$ & 83.92 & 73.39 & 81.86 & 72.81 & 82.21 & 74.03 \\
\hline$p=4$ & 84.30 & 71.52 & 83.01 & 71.41 & 78.38 & 70.78 \\
\hline $\mathrm{P}(\mathrm{AIC})$ & 72.50 & 72.08 & 71.86 & 71.43 & 71.10 & 70.39 \\
\hline & \multicolumn{6}{|c|}{ Group 1} \\
\hline Total Number of country pairs & \multicolumn{2}{|c|}{136} & \multicolumn{2}{|c|}{120} & \multicolumn{2}{|c|}{120} \\
\hline$p=0$ & 67.65 & 67.65 & 65.83 & 65.83 & 70.00 & 70.00 \\
\hline$p=1$ & 81.62 & 77.21 & 85.00 & 80.83 & 81.67 & 78.33 \\
\hline$p=2$ & 86.03 & 77.21 & 84.17 & 76.67 & 83.33 & 77.50 \\
\hline$p=3$ & 95.59 & 86.76 & 92.50 & 75.83 & 87.50 & 79.17 \\
\hline$p=4$ & 94.12 & 81.62 & 88.33 & 75.83 & 85.83 & 75.83 \\
\hline $\mathrm{P}(\mathrm{AIC})$ & 70.59 & 70.59 & 71.67 & 70.83 & 73.33 & 73.33 \\
\hline & \multicolumn{6}{|c|}{ Group 2} \\
\hline Total Number of country pairs & \multicolumn{2}{|c|}{253} & \multicolumn{2}{|c|}{253} & \multicolumn{2}{|c|}{210} \\
\hline$p=0$ & 71.54 & 71.54 & 70.36 & 70.36 & 75.71 & 75.71 \\
\hline$p=1$ & 86.56 & 83.40 & 82.21 & 79.05 & 86.19 & 83.81 \\
\hline$p=2$ & 86.17 & 79.84 & 84.19 & 79.05 & 89.05 & 83.81 \\
\hline$p=3$ & 85.77 & 77.87 & 84.98 & 77.87 & 90.95 & 81.43 \\
\hline$p=4$ & 83.40 & 75.49 & 84.58 & 74.31 & 89.05 & 79.05 \\
\hline $\mathrm{P}(\mathrm{AIC})$ & 74.31 & 73.52 & 72.73 & 72.33 & 79.05 & 78.57 \\
\hline & \multicolumn{6}{|c|}{ Group 3} \\
\hline Total Number of country pairs & \multicolumn{2}{|c|}{105} & \multicolumn{2}{|c|}{105} & \multicolumn{2}{|c|}{28} \\
\hline$p=0$ & 52.38 & 52.38 & 48.57 & 48.57 & 57.14 & 57.14 \\
\hline$p=1$ & 77.14 & 67.62 & 62.86 & 57.14 & 71.43 & 67.86 \\
\hline$p=2$ & 77.14 & 63.81 & 69.52 & 60.00 & 75.00 & 71.43 \\
\hline$p=3$ & 82.86 & 67.62 & 74.29 & 55.24 & 85.71 & 71.43 \\
\hline$p=4$ & 81.90 & 65.71 & 80.95 & 55.24 & 75.00 & 71.43 \\
\hline $\mathrm{P}(\mathrm{AIC})$ & 60.00 & 58.10 & 57.14 & 55.24 & 71.43 & 67.86 \\
\hline & \multicolumn{6}{|c|}{ Group 4} \\
\hline Total Number of country pairs & \multicolumn{2}{|c|}{36} & & & & \\
\hline$p=0$ & 94.44 & 94.44 & 97.22 & 97.22 & 100.00 & 100.00 \\
\hline$p=1$ & 91.67 & 91.67 & 94.44 & 94.44 & 100.00 & 100.00 \\
\hline$p=2$ & 88.89 & 91.67 & 97.22 & 94.44 & 100.00 & 100.00 \\
\hline$p=3$ & 91.67 & 91.67 & 97.22 & 97.22 & 100.00 & 100.00 \\
\hline$p=4$ & 91.67 & 91.67 & 97.22 & 97.22 & 100.00 & 100.00 \\
\hline $\mathrm{P}(\mathrm{AIC})$ & 91.67 & 91.67 & 97.22 & 97.22 & 100.00 & 100.00 \\
\hline & & & & & & \\
\hline Total Number of country pairs & & & & & & \\
\hline$p=0$ & 87.39 & 87.39 & 87.94 & 87.94 & 85.71 & 85.71 \\
\hline$p=1$ & 88.89 & 86.94 & 90.00 & 87.78 & 100 & 95.24 \\
\hline$p=2$ & 88.29 & 85.74 & 90.00 & 85.56 & 85.71 & 80.95 \\
\hline$p=3$ & 90.54 & 83.93 & 91.75 & 86.35 & 80.95 & 80.95 \\
\hline$p=4$ & 89.94 & 82.28 & 90.79 & 83.33 & 80.95 & 80.95 \\
\hline $\mathrm{P}(\mathrm{AIC})$ & 86.94 & 86.94 & 87.30 & 87.30 & 85.71 & 85.71 \\
\hline
\end{tabular}


Table 13: Proportion of Insignificant Short run and Long Run Intercept Terms in the Output Growth Gap Regressions - Maddison Series

\begin{tabular}{|c|c|c|c|c|c|c|}
\hline \multirow{4}{*}{\begin{tabular}{|l|} 
Group \\
Sample period \\
Tests/Significant \\
Level \\
\end{tabular}} & & & & & \multicolumn{2}{|c|}{ (per cent) } \\
\hline & \multirow{2}{*}{\multicolumn{2}{|c|}{$\frac{\text { Advanced }}{1870-2000(\mathrm{~T}=131)}$}} & \multirow{2}{*}{\multicolumn{2}{|c|}{$\begin{array}{c}\text { South Europe } \\
1923-2000(T=78)\end{array}$}} & \multirow{2}{*}{\multicolumn{2}{|c|}{$\begin{array}{c}\text { Latin America } \\
1900-2000(\mathrm{~T}=101)\end{array}$}} \\
\hline & & & & & & \\
\hline & SR & LR & SR & LR & SR & LR \\
\hline $\begin{array}{l}\text { Number of } \\
\text { countries } \\
\text { Number of country } \\
\text { pairs }\end{array}$ & \multicolumn{2}{|c|}{17} & \multicolumn{2}{|c|}{5} & \multicolumn{2}{|c|}{8} \\
\hline$p=0$ & 97.79 & 97.79 & 100.00 & 100.00 & 100.00 & 96.43 \\
\hline$p=1$ & 98.53 & 98.53 & 100.00 & 100.00 & 96.43 & 96.43 \\
\hline$P=2$ & 97.79 & 97.79 & 100.00 & 100.00 & 96.43 & 96.43 \\
\hline$P=3$ & 97.79 & 95.59 & 100.00 & 100.00 & 96.43 & 96.43 \\
\hline$P=4$ & 97.06 & 97.06 & 100.00 & 100.00 & 100.00 & 96.43 \\
\hline$P(A I C)$ & 97.06 & 95.59 & 100.00 & 100.00 & 100.00 & 96.43 \\
\hline
\end{tabular}




\section{Table A: Critical Values for the Unit Root Tests}

\section{With intercept only}

\begin{tabular}{|c|c|c|c|c|c|c|}
\hline \multirow{3}{*}{$\begin{array}{l}\text { Significance level } \\
\text { Tests/Sample Sizes }\end{array}$} & \multicolumn{3}{|c|}{ PWT data } & \multicolumn{3}{|c|}{ Maddison data } \\
\hline & \multicolumn{6}{|c|}{$5 \%$} \\
\hline & 30 & 40 & 50 & 78 & 101 & 131 \\
\hline ADF & -2.9637 & -2.8976 & -2.9008 & -2.9532 & -2.8814 & -2.8901 \\
\hline ADF-GLS & -2.3968 & -2.3149 & -2.2415 & -2.1925 & -2.1340 & -2.0906 \\
\hline ADF-WS & -2.6086 & -2.5919 & -2.5485 & -2.6008 & -2.5806 & -2.543 \\
\hline Significance level & \multicolumn{6}{|c|}{$10 \%$} \\
\hline Tests/Sample Sizes & 30 & 40 & 50 & 78 & 101 & 131 \\
\hline ADF & -2.6353 & -2.5829 & -2.5760 & -2.6215 & -2.5927 & -2.592 \\
\hline ADF-GLS & -2.0991 & -2.0193 & -1.9490 & -1.8510 & -1.8300 & -1.78 \\
\hline ADF-WS & -2.2752 & -2.2775 & -2.2534 & -2.2694 & -2.2786 & -2.2511 \\
\hline
\end{tabular}

With an intercept and a linear trend

\section{PWT data}

Significance level

Tests/Sample Sizes

ADF

ADF-GLS

ADF-WS

Significance level

Tests/Sample Sizes

ADF

ADF-GLS

ADF-WS

\begin{tabular}{cccccc} 
& PWT data & \multicolumn{5}{c}{ Maddison data } \\
\cline { 2 - 5 } $\mathbf{3 0}$ & $\mathbf{4 0}$ & $\mathbf{5 0}$ & $\mathbf{7 8}$ & $\mathbf{1 0 1}$ & $\mathbf{1 3 1}$ \\
-3.5696 & -3.5308 & -3.5114 & -3.4573 & -3.429 & -3.4569 \\
-3.4116 & -3.2579 & -3.1634 & -3.0805 & -2.9967 & -2.9781 \\
-3.4318 & -3.3426 & -3.2957 & -3.2855 & -3.2318 & -3.2361 \\
\multicolumn{7}{c}{$\mathbf{1 0 \%}$} \\
$\mathbf{3 0}$ & $\mathbf{4 0}$ & $\mathbf{5 0}$ & $\mathbf{7 8}$ & $\mathbf{1 0 1}$ & 131 \\
-3.2282 & -3.1898 & -3.1697 & -3.1656 & -3.1340 & -3.1556 \\
-3.0653 & -2.9614 & -2.8488 & -2.7766 & -2.7009 & -2.6939 \\
-3.0757 & -3.0317 & -2.9600 & -2.9622 & -2.9209 & -2.9355
\end{tabular}

Notes: Critical values for the test statistics are computed as follows. For the ADF statistic, the critical values for the statistic are computed based on the empirical distribution of the t-statistic of the level variable in the ADF regression of $\Delta x_{i t}$ on $x_{i t-1}$, deterministic components, and lagged values of $\Delta x_{i t}$, where $x_{i t}$ is generated as $x_{i t}=x_{i t-1}+\varepsilon_{i t}$ with $\varepsilon_{i t} \sim$ iidN $(0,1)$. The ADF-GLS statistic is computed based on the t-statistic of the level variable in the ADF regression applied to a demeaned or de-trended variable (depending on the case being considered) as proposed in Elliott, Rothenberg and Stock (1996). For the intercept case, the value of $c$ is set equal to 7, and 13.5 for the case with intercept and linear trend. Note that, for the case when there are no intercept and trend, the critical values of the ADF and ADF-GLS statistics coincide. The critical values for the weighted symmetric ADF statistics are computed based on the empirical distribution of the test statistic as proposed in Park and Fuller (1995), The discussion of the ADFGLS and weighted symmetric ADF statistics can be found in the Appendix. The critical values are computed for the cases where the deterministic components include intercept only, and intercept and linear trend. The simulations are carried out with 10,000 replications. 
Figure 1

\section{Log Real Per Capita Output for the World Economies (PWT Data)}

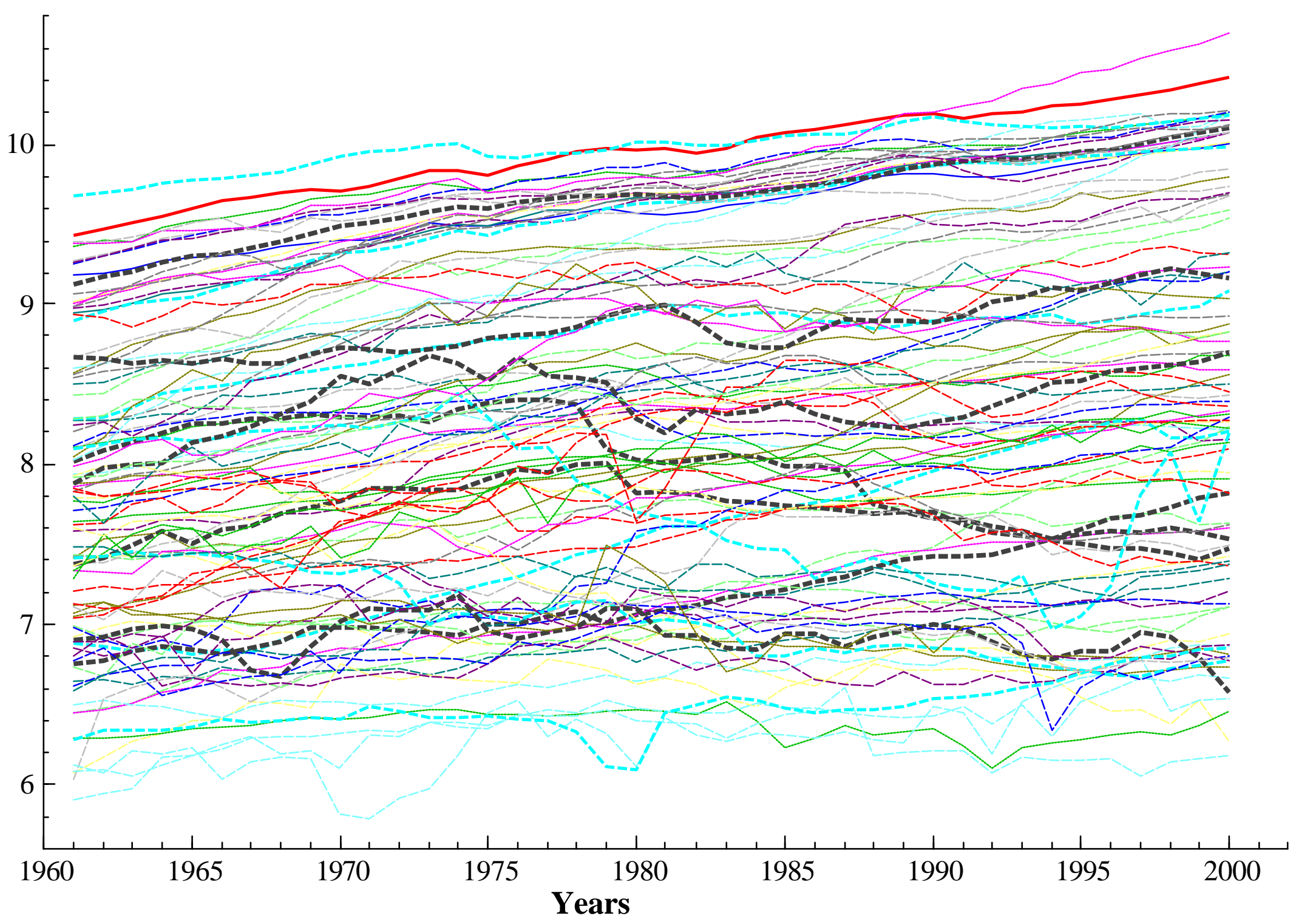


Figure 2

Log Real Per Capita Output for European Economies (Group 1, PWT Data)

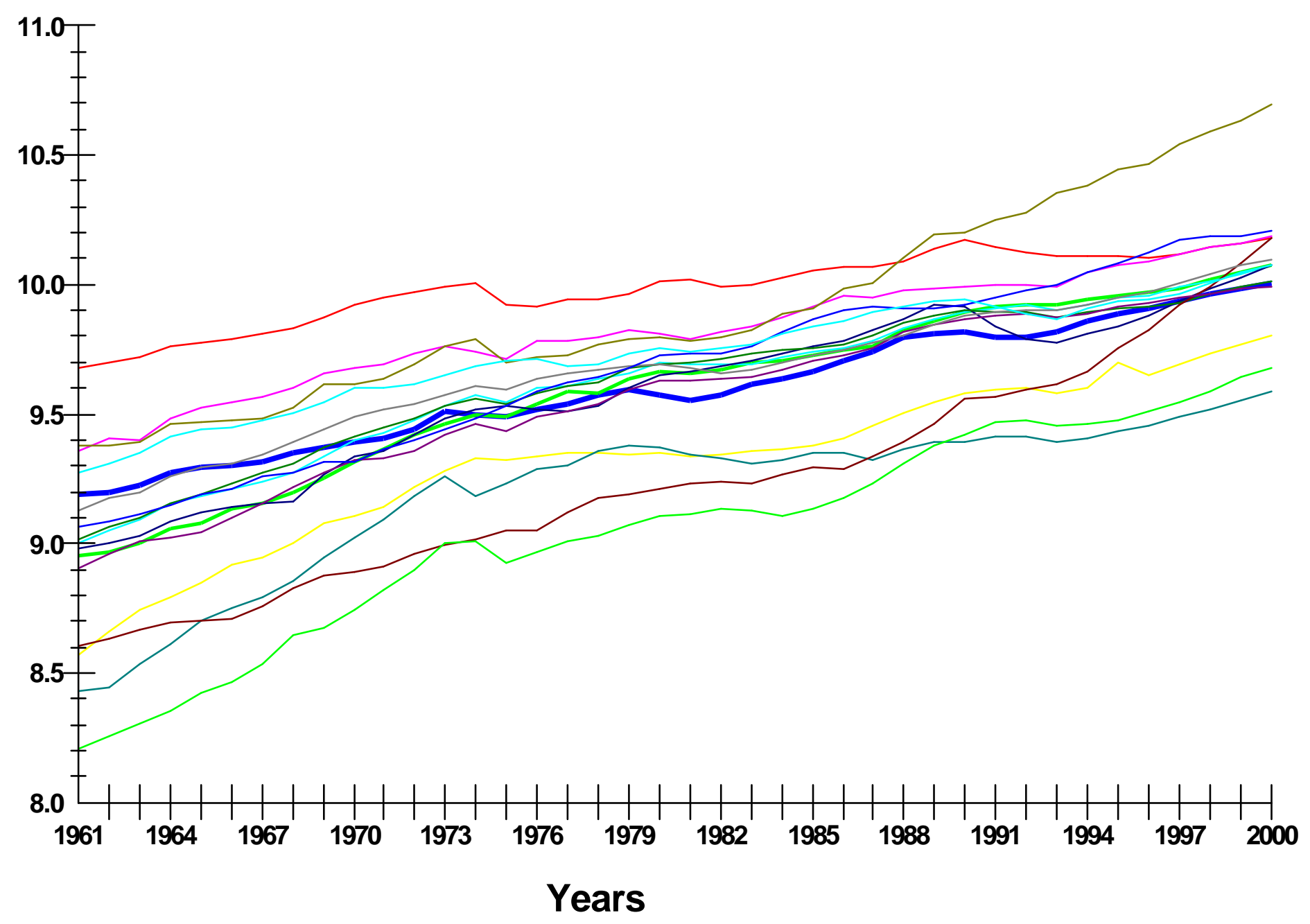

/ UK

Austria

Belgium

Switzerland

/ Denmark Spain

/ Finland

/ France

/ Greece

/ Ireland

/ Italy

Luxembourg

Netherlands

/ Norway

Portugal

Sweden 


\section{Figure 3}

\section{Log Real Per Capita Output for North and Latin Economies (Group 2, PWT Data)}

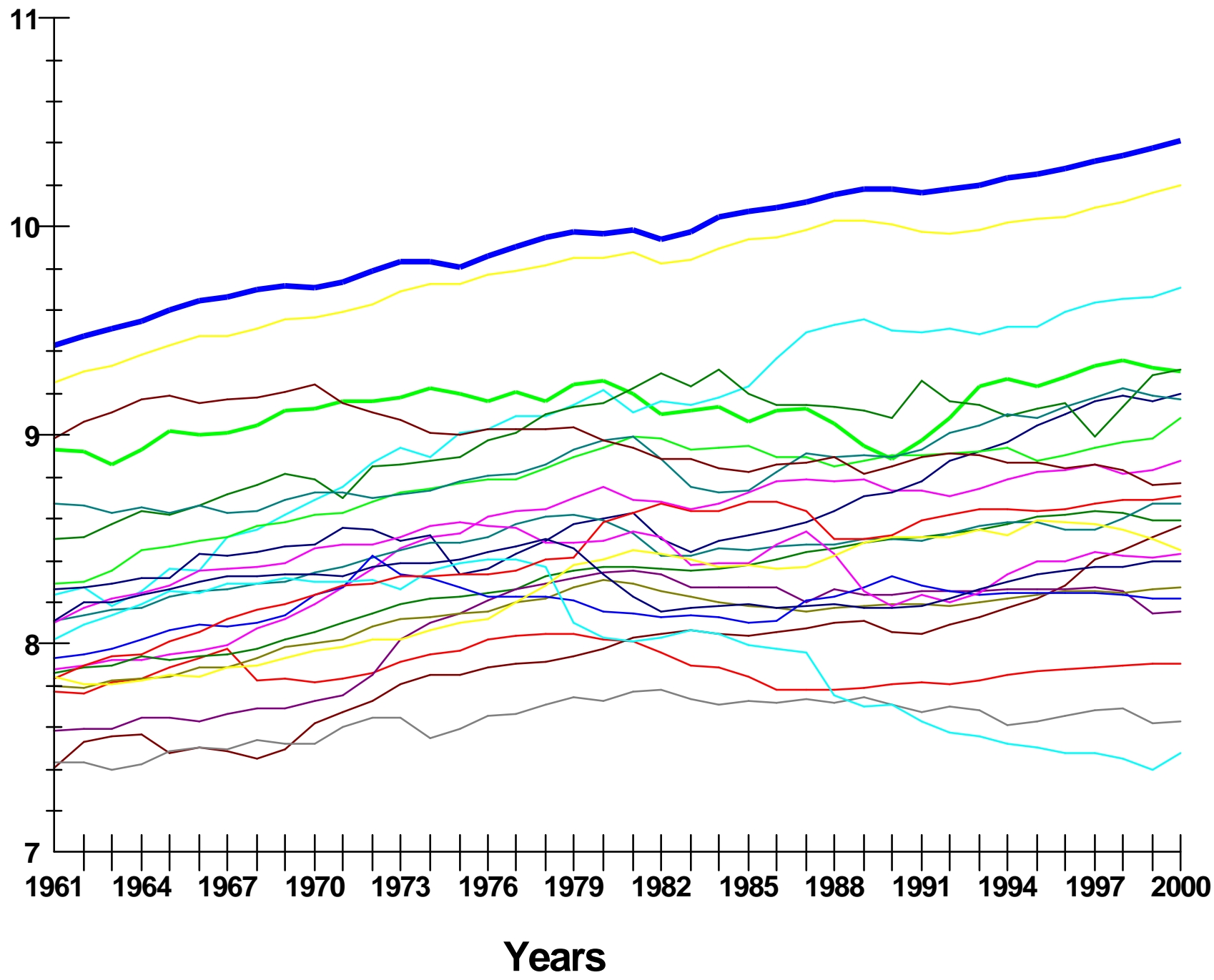

/ USA

Argentina

Barbados

Bolivia

Brazil

Canada

/ Chile

Colombia

Costa Rica

Dominican Rep.

Ecuador

Guatemala

Honduras

Jamaica

Mexico

Nicaragua

Panama

Peru

Paraguay

El Salvador

Trinidad \& Tobago

Uruguay

Venezuela 
Figure 4

Log Real Per Capita Output for Asia, Australia and New Zealand Economies (Group 3, PWT Data)

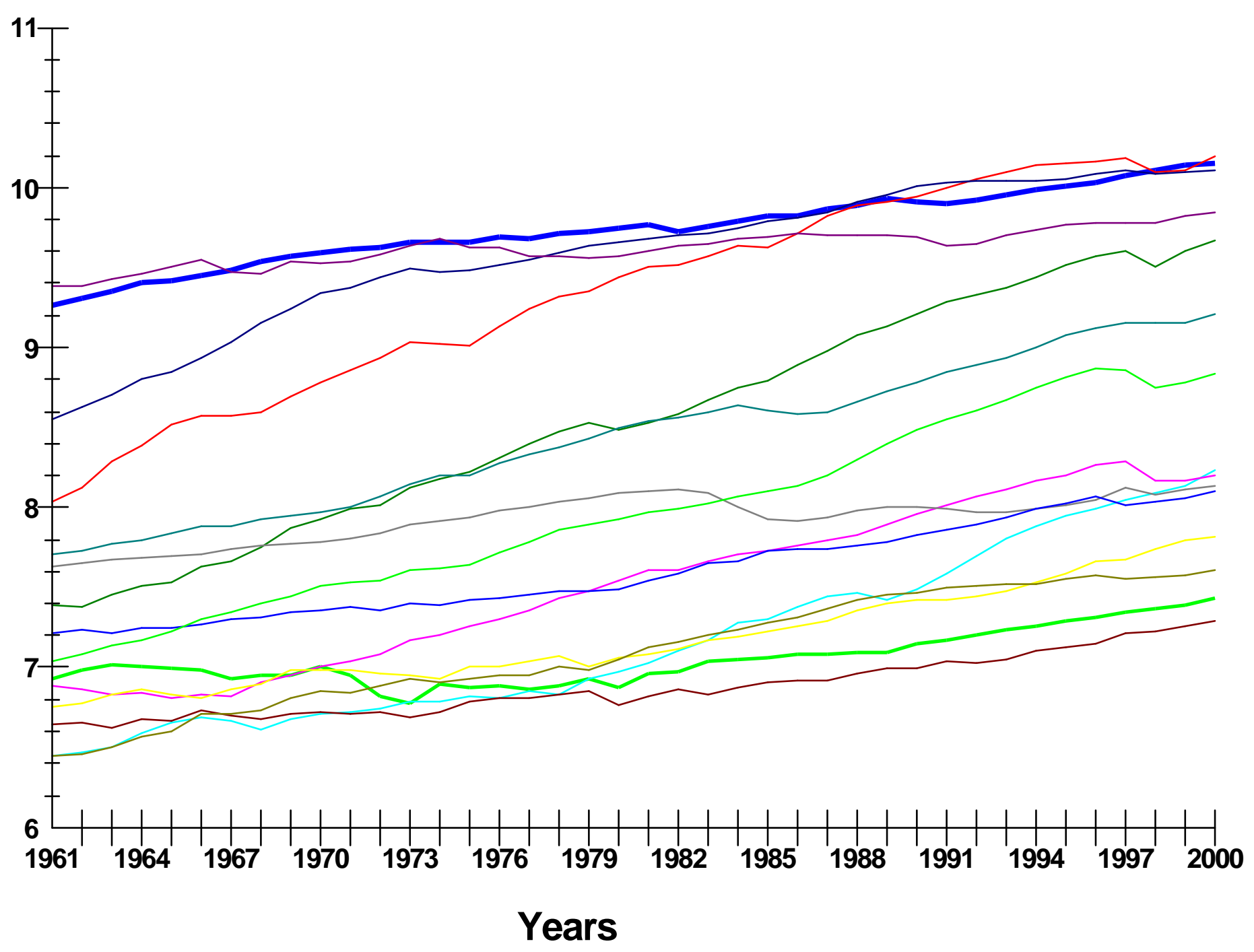

- Australia

Bangladesh

China

/ Hong Kong

/ Indonesia

India

/ Japan

/ Korea

/ Malaysia

/ Nepal

/ New Zealand

/ Pakistan

Philippines

/ Sri Lanka

Thailand 
Figure 5

Log Real Per Capita Output for Middle East and North African Economies (Group 4, PWT Data)

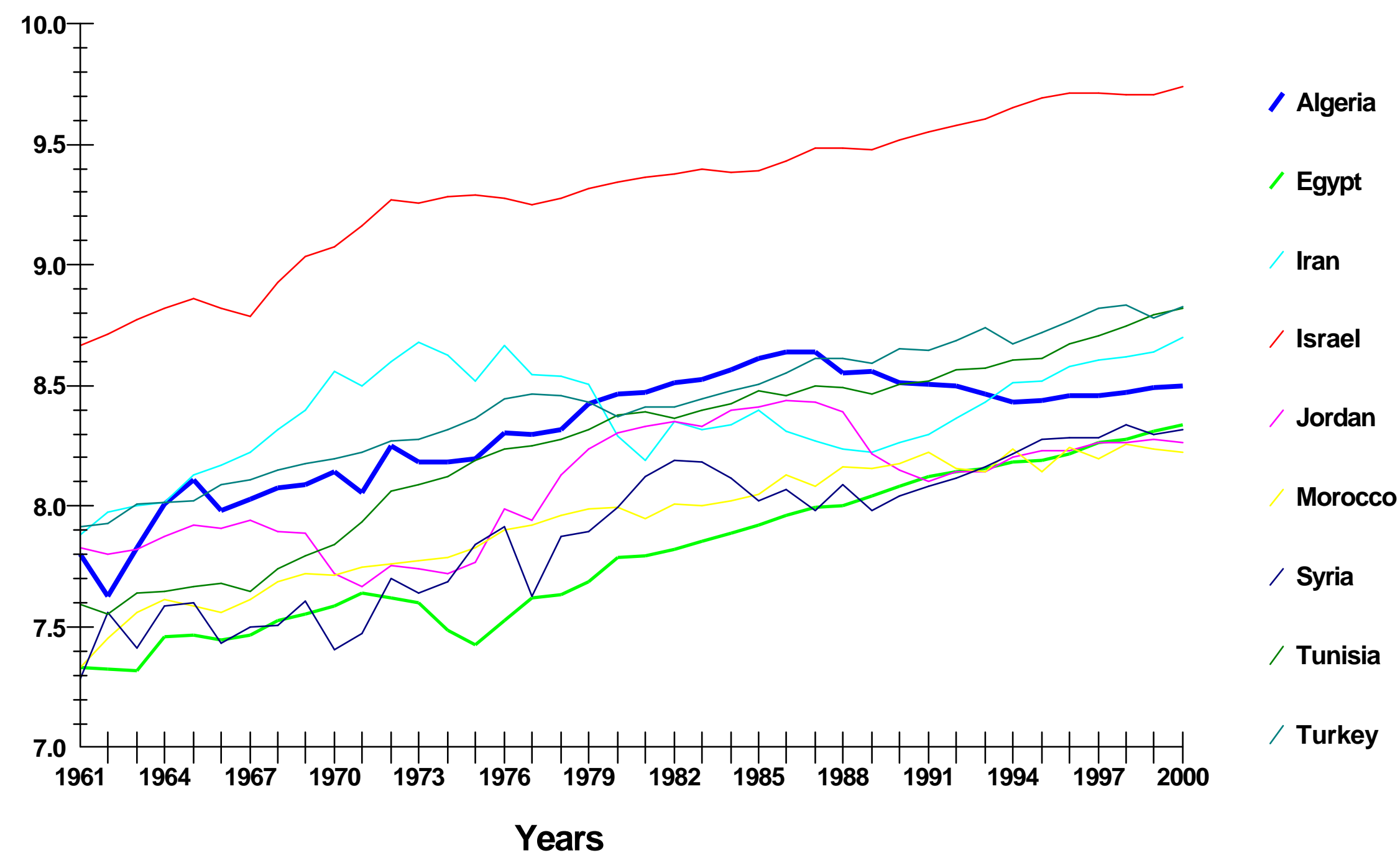




\section{Figure 6}

Log Real Per Capita Output for Rest of the World Economies (Group 5, PWT Data)

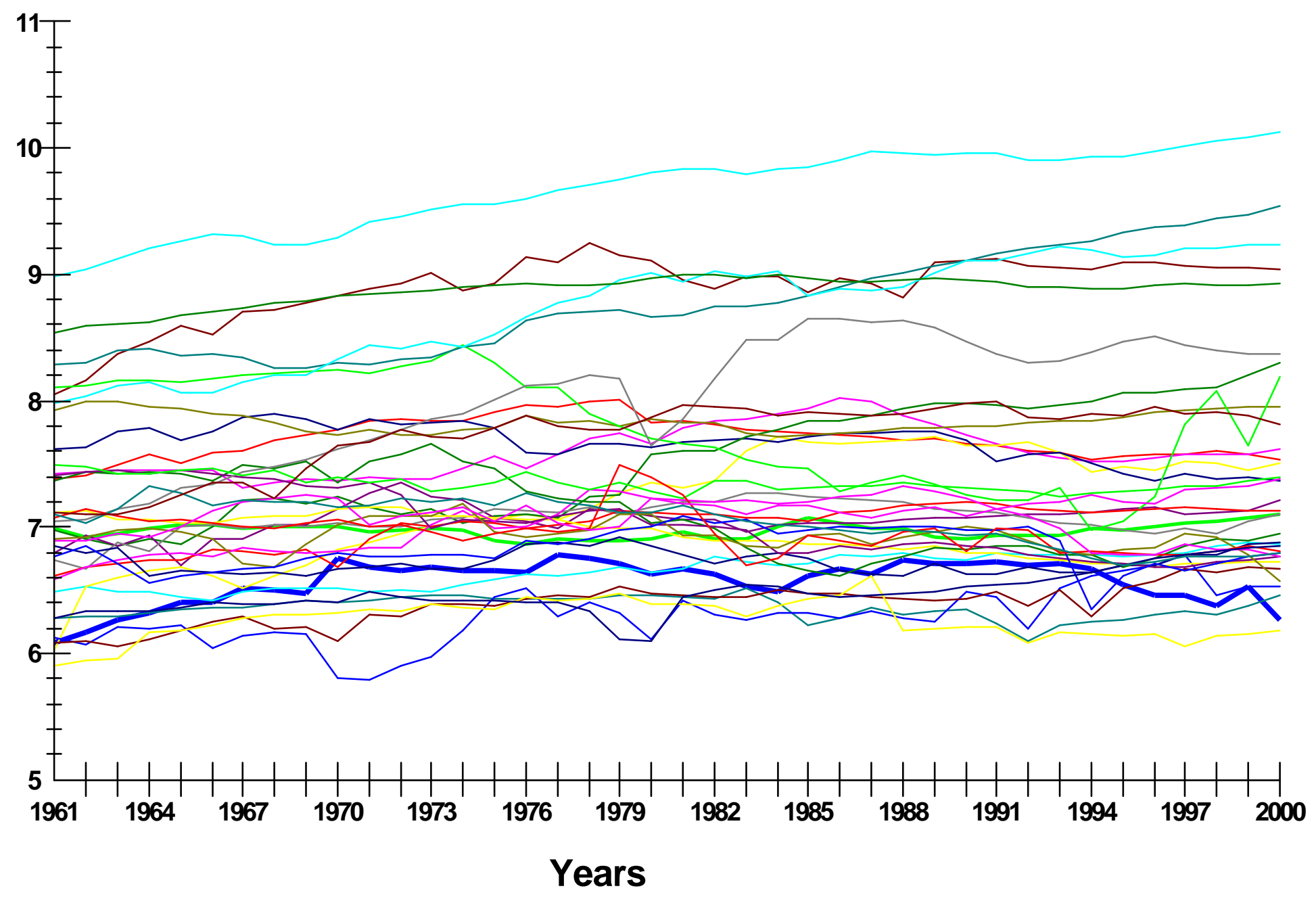

/ Kenya

Lesotho

Madagascar 


\section{Figure 7}

\section{Log Real Per Capita Output for Advanced Economies (Maddison Data)}

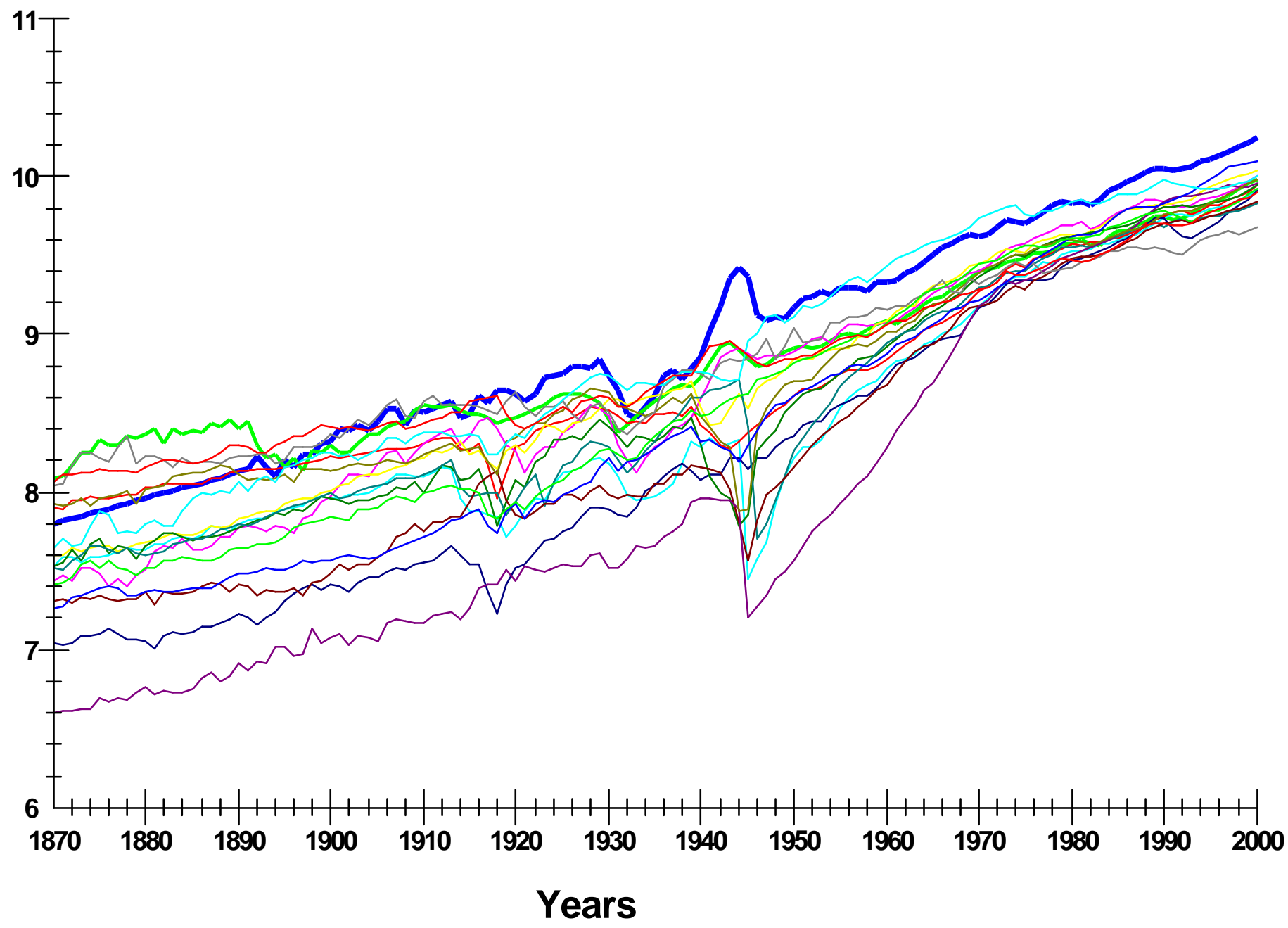

USA

Australia Austria

Belgium

Canada

Denmark

Finland

France

Germany

/ Italy

/ Japan

Netherlands

New Zealand Norway

Sweden

Switzerland

UK 


\section{Figure 8}

\section{Log Real Per Capita Output for South European Economies (Maddison Data)}

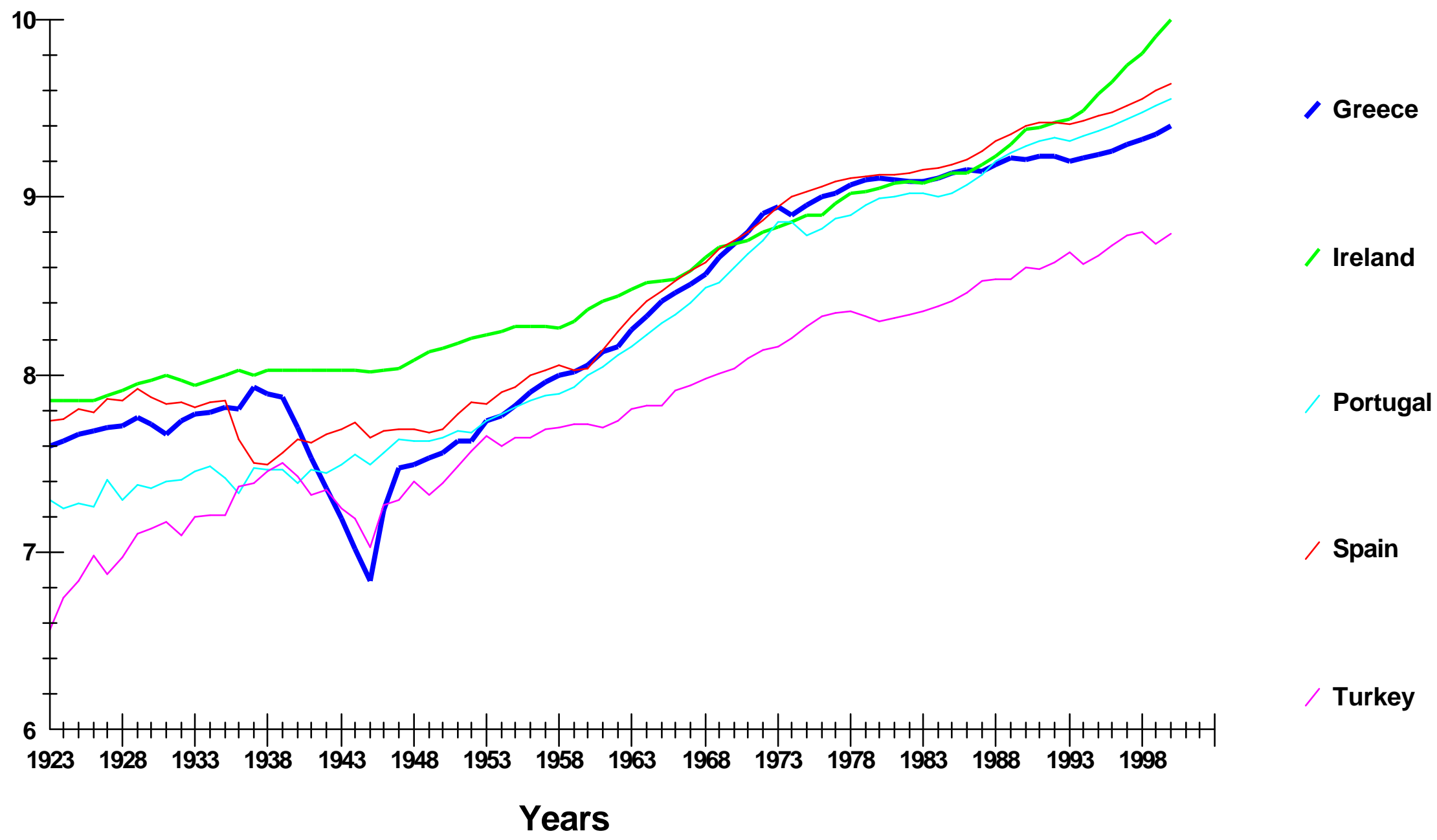


Figure 9

Log Real Per Capita Output for Latin American Economies (Maddison Data)

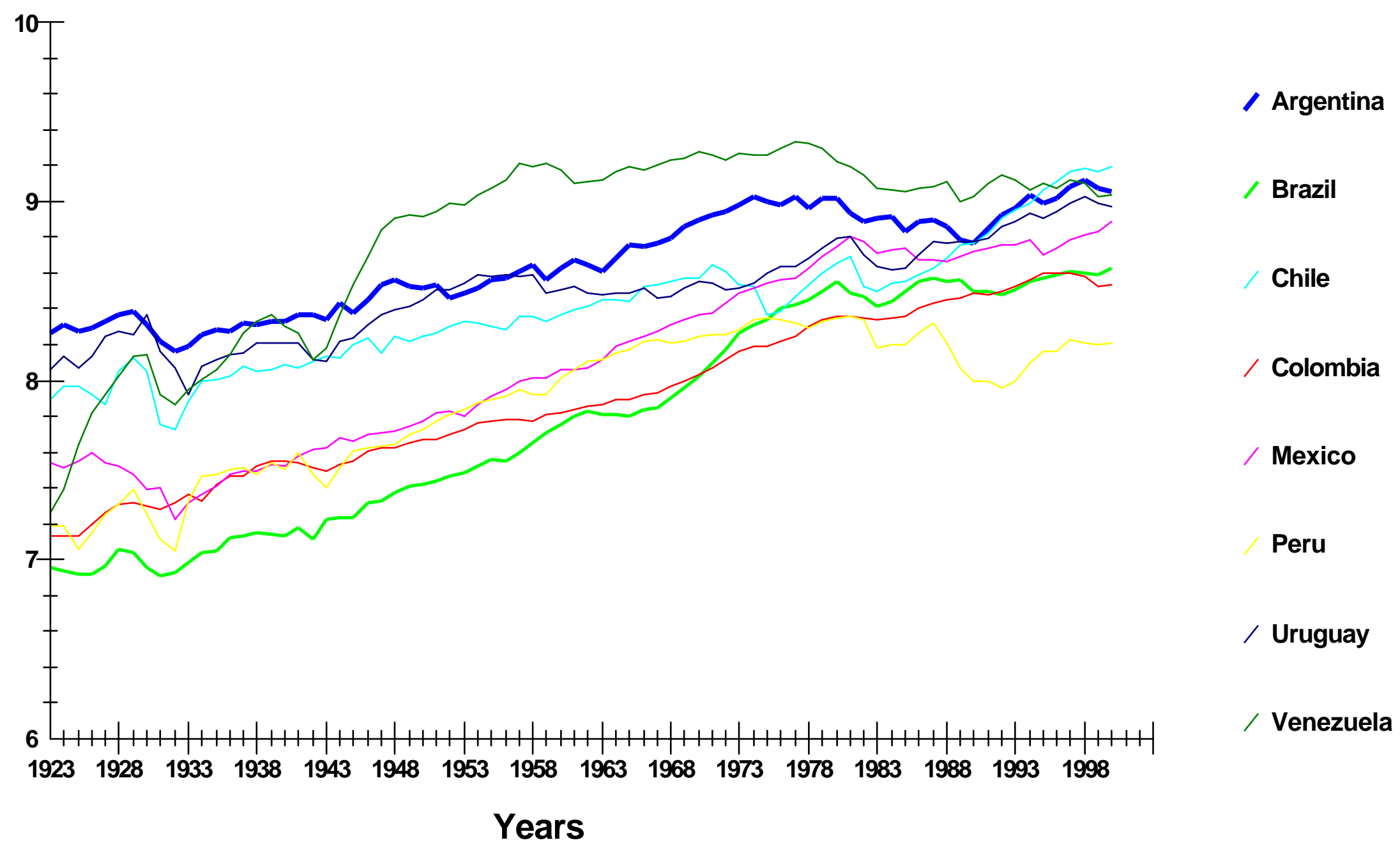


Figure 10

Equal and Population Weighted Mean Difference Coefficients of Log Per Capita Output - 1961-2000, PWT Series
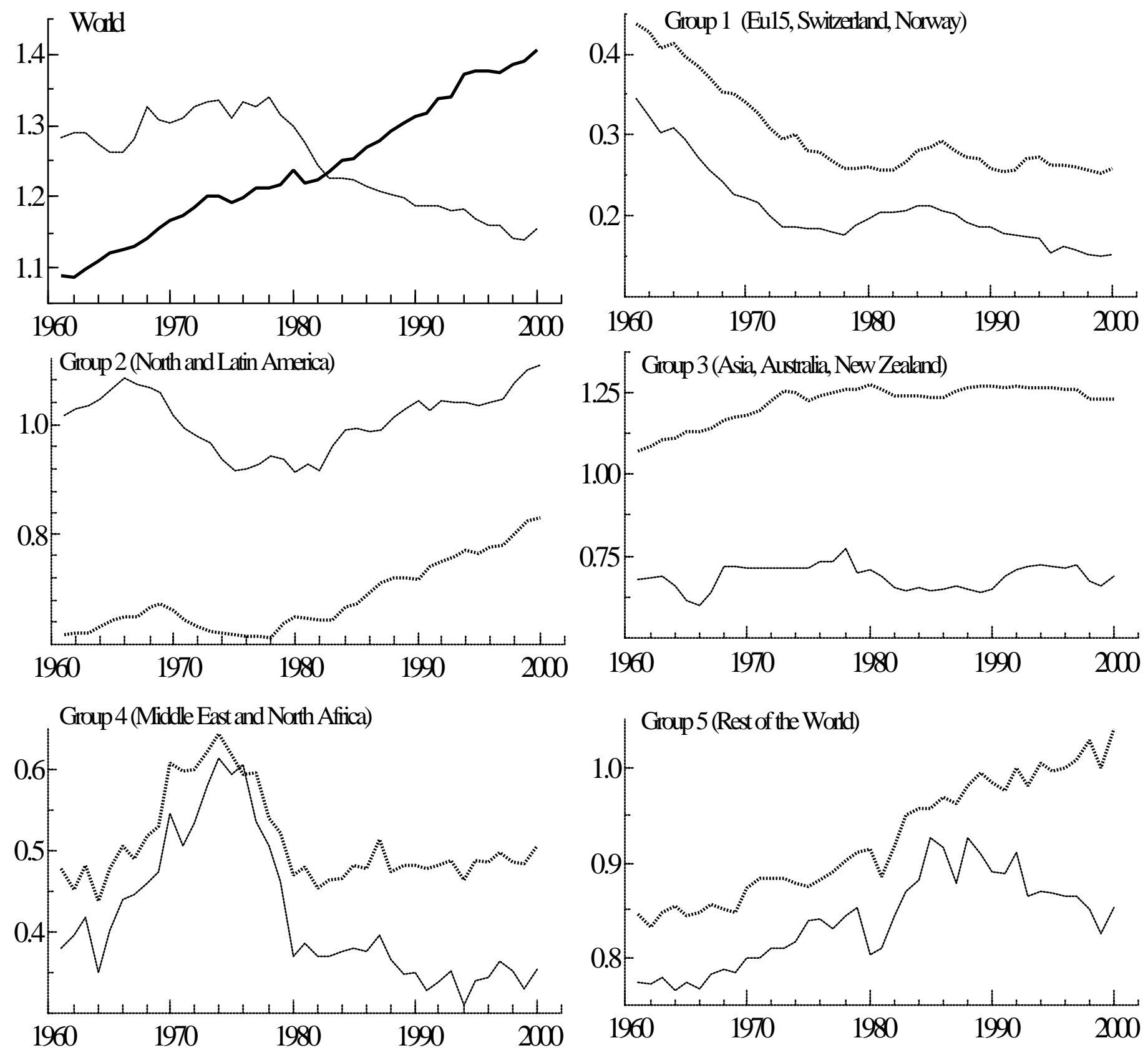

- - winum $\mathrm{MD}$ (Equal weight) $-\mathrm{MD}$ (Population weight) 


\title{
CESifo Working Paper Series
}

\author{
(for full list see www.cesifo.de)
}

1245 Rafael Lalive and Alois Stutzer, Approval of Equal Rights and Gender Differences in Well-Being, July 2004

1246 Paolo M. Panteghini, Wide vs. Narrow Tax Bases under Optimal Investment Timing, July 2004

1247 Marika Karanassou, Hector Sala, and Dennis J. Snower, Unemployment in the European Union: Institutions, Prices, and Growth, July 2004

1248 Engin Dalgic and Ngo Van Long, Corrupt Local Government as Resource Farmers: The Helping Hand and the Grabbing Hand, July 2004

1249 Francesco Giavazzi and Guido Tabellini, Economic and Political Liberalizations, July 2004

1250 Yin-Wong Cheung and Jude Yuen, An Output Perspective on a Northeast Asia Currency Union, August 2004

1251 Ralf Elsas, Frank Heinemann, and Marcel Tyrell, Multiple but Asymmetric Bank Financing: The Case of Relationship Lending, August 2004

1252 Steinar Holden, Wage Formation under Low Inflation, August 2004

1253 Ngo Van Long and Gerhard Sorger, Insecure Property Rights and Growth: The Roles of Appropriation Costs, Wealth Effects, and Heterogeneity, August 2004

1254 Klaus Wälde and Pia Weiß, International Competition, Slim Firms and Wage Inequality, August 2004

1255 Jeremy S. S. Edwards and Alfons J. Weichenrieder, How Weak is the Weakest-Link Principle? On the Measurement of Firm Owners' Control Rights, August 2004

1256 Guido Tabellini, The Role of the State in Economic Development, August 2004

1257 François Larmande and Jean-Pierre Ponssard, EVA and the Controllability-congruence Trade-off: An Empirical Investigation, August 2004

1258 Vesa Kanniainen and Jenni Pääkkönen, Anonymous Money, Moral Sentiments and Welfare, August 2004

1259 Panu Poutvaara and Andreas Wagener, Why is the Public Sector More Labor-Intensive? A Distortionary Tax Argument, August 2004

1260 Lars P. Feld and Stefan Voigt, Making Judges Independent - Some Proposals Regarding the Judiciary, August 2004 
1261 Joop Hartog, Hans van Ophem, and Simona Maria Bajdechi, How Risky is Investment in Human Capital?, August 2004

1262 Thomas Eichner and Rüdiger Pethig, Efficient Nonanthropocentric Nature Protection, August 2004

1263 David-Jan Jansen and Jakob de Haan, Look Who's Talking: ECB Communication during the First Years of EMU, August 2004

1264 David F. Bradford, The X Tax in the World Economy, August 2004

1265 Hans-Werner Sinn, Migration, Social Standards and Replacement Incomes. How to Protect Low-income Workers in the Industrialized Countries against the Forces of Globalization and Market Integration, August 2004

1266 Wolfgang Leininger, Fending off one Means Fending off all: Evolutionary Stability in Submodular Games, August 2004

1267 Antoine Bommier and Bertrand Villeneuve, Risk Aversion and the Value of Risk to Life, September 2004

1268 Harrie A. A. Verbon and Lex Meijdam, Too Many Migrants, Too Few Services: A Model of Decision-making on Immigration and Integration with Cultural Distance, September 2004

1269 Thomas Eichner and Rüdiger Pethig, Economic Land Use, Ecosystem Services and Microfounded Species Dynamics, September 2004

1270 Federico Revelli, Performance Rating and Yardstick Competition in Social Service Provision, September 2004

1271 Gerhard O. Orosel and Klaus G. Zauner, Vertical Product Differentiation When Quality is Unobservable to Buyers, September 2004

1272 Christoph Böhringer, Stefan Boeters, and Michael Feil, Taxation and Unemployment: An Applied General Equilibrium Approach, September 2004

1273 Assaf Razin and Efraim Sadka, Welfare Migration: Is the Net Fiscal Burden a Good Measure of its Economics Impact on the Welfare of the Native-Born Population?, September 2004

1274 Tomer Blumkin and Volker Grossmann, Ideological Polarization, Sticky Information, and Policy Reforms, September 2004

1275 Katherine Baicker and Nora Gordon, The Effect of Mandated State Education Spending on Total Local Resources, September 2004

1276 Gabriel J. Felbermayr and Wilhelm Kohler, Exploring the Intensive and Extensive Margins of World Trade, September 2004 
1277 John Burbidge, Katherine Cuff and John Leach, Capital Tax Competition with Heterogeneous Firms and Agglomeration Effects, September 2004

1278 Joern-Steffen Pischke, Labor Market Institutions, Wages and Investment, September 2004

1279 Josef Falkinger and Volker Grossmann, Institutions and Development: The Interaction between Trade Regime and Political System, September 2004

1280 Paolo Surico, Inflation Targeting and Nonlinear Policy Rules: The Case of Asymmetric Preferences, September 2004

1281 Ayal Kimhi, Growth, Inequality and Labor Markets in LDCs: A Survey, September 2004

1282 Robert Dur and Amihai Glazer, Optimal Incentive Contracts for a Worker who Envies his Boss, September 2004

1283 Klaus Abberger, Nonparametric Regression and the Detection of Turning Points in the Ifo Business Climate, September 2004

1284 Werner Güth and Rupert Sausgruber, Tax Morale and Optimal Taxation, September 2004

1285 Luis H. R. Alvarez and Erkki Koskela, Does Risk Aversion Accelerate Optimal Forest Rotation under Uncertainty?, September 2004

1286 Giorgio Brunello and Maria De Paola, Market Failures and the Under-Provision of Training, September 2004

1287 Sanjeev Goyal, Marco van der Leij and José Luis Moraga-González, Economics: An Emerging Small World?, September 2004

1288 Sandro Maffei, Nikolai Raabe and Heinrich W. Ursprung, Political Repression and Child Labor: Theory and Empirical Evidence, September 2004

1289 Georg Götz and Klaus Gugler, Market Concentration and Product Variety under Spatial Competition: Evidence from Retail Gasoline, September 2004

1290 Jonathan Temple and Ludger Wößmann, Dualism and Cross-Country Growth Regressions, September 2004

1291 Ravi Kanbur, Jukka Pirttilä and Matti Tuomala, Non-Welfarist Optimal Taxation and Behavioral Public Economics, October 2004

1292 Maarten C. W. Janssen, José Luis Moraga-González and Matthijs R. Wildenbeest, Consumer Search and Oligopolistic Pricing: An Empirical Investigation, October 2004

1293 Kira Börner and Christa Hainz, The Political Economy of Corruption and the Role of Financial Institutions, October 2004 
1294 Christoph A. Schaltegger and Lars P. Feld, Do Large Cabinets Favor Large Governments? Evidence from Swiss Sub-Federal Jurisdictions, October 2004

1295 Marc-Andreas Mündler, The Existence of Informationally Efficient Markets When Individuals Are Rational, October 2004

1296 Hendrik Jürges, Wolfram F. Richter and Kerstin Schneider, Teacher Quality and Incentives: Theoretical and Empirical Effects of Standards on Teacher Quality, October 2004

1297 David S. Evans and Michael Salinger, An Empirical Analysis of Bundling and Tying: Over-the-Counter Pain Relief and Cold Medicines, October 2004

1298 Gershon Ben-Shakhar, Gary Bornstein, Astrid Hopfensitz and Frans van Winden, Reciprocity and Emotions: Arousal, Self-Reports, and Expectations, October 2004

1299 B. Zorina Khan and Kenneth L. Sokoloff, Institutions and Technological Innovation During Early Economic Growth: Evidence from the Great Inventors of the United States, 1790 - 1930, October 2004

1300 Piero Gottardi and Roberto Serrano, Market Power and Information Revelation in Dynamic Trading, October 2004

1301 Alan V. Deardorff, Who Makes the Rules of Globalization?, October 2004

1302 Sheilagh Ogilvie, The Use and Abuse of Trust: Social Capital and its Deployment by Early Modern Guilds, October 2004

1303 Mario Jametti and Thomas von Ungern-Sternberg, Disaster Insurance or a Disastrous Insurance - Natural Disaster Insurance in France, October 2004

1304 Pieter A. Gautier and José Luis Moraga-González, Strategic Wage Setting and Coordination Frictions with Multiple Applications, October 2004

1305 Julia Darby, Anton Muscatelli and Graeme Roy, Fiscal Federalism, Fiscal Consolidations and Cuts in Central Government Grants: Evidence from an Event Study, October 2004

1306 Michael Waldman, Antitrust Perspectives for Durable-Goods Markets, October 2004

1307 Josef Honerkamp, Stefan Moog and Bernd Raffelhüschen, Earlier or Later: A General Equilibrium Analysis of Bringing Forward an Already Announced Tax Reform, October 2004

1308 M. Hashem Pesaran, A Pair-Wise Approach to Testing for Output and Growth Convergence, October 2004 